\title{
Color y luz en Ciudad Abierta. La apropiación espacial de la extensión territorial
}

\section{Colour and light in Open City. The spatial appropriation of territorial extension}

\section{Daniel Danés Grases}

Universidad Politécnica de Madrid, España

danes@proyeco.es

https://orcid.org/0000-0002-5431-2590

María José Pizarro Juanas

Universidad Politécnica de Madrid, España

mariajose.pizarro@upm.es

https://orcid.org/0000-0002-4658-1731

Joaquín Ibáñez Montoya

Universidad Politécnica de Madrid, España

joaquín.ibanez@upm.es

https://orcid.org/0000-0003-4609-8683

Frank Marcano Requena

Universidad Politécnica de Madrid, España

marcano.frank@gmail.es

https://orcid.org/0000-0003-1080-7935 


\title{
Resumen
}

El estado de arte del color en la Escuela de Arquitectura y Diseño de Valparaíso no ha sido reconocido. Desde su fundación se analiza el fenómeno cromático en sus proyectos como un hecho experimentable de la acción de la luz sobre la arquitectura. Su aprendizaje se realiza a través de técnicas innovadoras que se resumen en una matriz analítica de doble entrada relacionando modelos de enseñanza con finalidades cromáticas. La cuestión del color y la luz en Ciudad Abierta tiene la cobertura que merece como laboratorio de ensayo que es.

El sentido de ser americano en la Escuela de Valparaíso está asimilado a la noción de punto estaca como un modo original de habitar un continente, donde lo cromático alcanza su espacio construido. La conciencia de americanidad se concentra en un horizonte vertical, expresado por la interacción de la luz y el espacio en atmósferas coloreadas que visibilizan la diversidad y complejidad de un territorio. A partir de límites lumínicos -cuyos colores están en una luz plena de atributos- se construye una lugaridad que identifica lo particular de cada lugar. El objetivo de esta inmersión sensorial es desvelar los componentes básicos de los efectos del color sobre un espacio visibilizado como luz con naturaleza continental. La arquitectura se reinventa en espacios lumínicos ecológicamente coloreados como una lectura sintética y cultural de un sitio.

La pedagógica innovadora de la Escuela de Valparaíso experimenta con el uso de la luz y el color como eje estructural de la materialización de la extensión del territorio mediante una enseñanza lúdica de la arquitectura. Su metodología toma carácter universal y categoría estética en una constante interrogación poética sobre la condición continental americana. Los colores lumínicos que construyen horizontes en el marco arquitectónico, y la presencia corporal que se vincula a través del juego y la palabra con la creación del lugar, son parte de la respuesta que contribuye a renovar un espíritu innovador predispuesto para el proyecto arquitectónico.

\section{Palabras clave: Ciudad Abierta; color; Escuela de Arquitectura y Diseño de Valparaiso}

\begin{abstract}
The use of colour at the Valparaíso School of Architecture and Design constitutes a state of the art that has hitherto not been recognised. Since its foundation, the chromatic phenomenon that can be found in the School's projects has been analysed as an experienceable action of light on architecture. It is taught through innovative techniques that are summarised in a double-entry analytical matrix linking teaching models to chromatic purposes. The issue of colour and light in the Open City has the publicity it deserves as the test laboratory that it is.

The sense of being American in the Valparaíso School is assimilated to the notion of the stake point as an original way of inhabiting a continent, where the chromatic reaches its built space. The consciousness of Americanity is concentrated on a vertical horizon, expressed by the interaction of light and space in coloured atmospheres that make a territory's diversity and complexity visible. A place is built using light limits, whose colours are in a light full of attributes, thus determining the particular nature of each place. The objective of this sensory immersion is to reveal the basic components of the effects of colour on a space made visible as light of a continental nature. Architecture reinvents itself in ecologically coloured light-filled spaces as a concise and cultural reading of a site.

The Valparaíso School's innovative pedagogical approach performs experiments using light and colour as the structural axis of the materialisation of the territory's extension. It thus teaches architectures in a playful manner. The methodology is of a universal nature and its aesthetics represent a constant poetic questioning regarding the condition of the American continent. The colours of the light enable building horizons in the architectural framework. These colours, together with bodily presence, linked to the creation of the place through play and words, partly contribute to the renewal of an innovative spirit predisposed to the architectural project.
\end{abstract}

\section{Key words: Open City; colour; School of Architecture and Design of Valparaíso}

\section{Para citar este artículo / To cite this article:}

DANES, D., PIZARRO, M.J., IBÁÑEZ, J., MARCANO, F. Color y luz en Ciudad Abierta. La apropiación espacial de la extensión territorial. En: [i2] Investigación e Innovación en Arquitectura y Territorio [en línea]. 2022, Vol.10, Núm. 1. ISSN: $2341-0515$. https://doi.org/10.14198/12.19791

Este trabajo se publica bajo una licencia de Creative Commons Reconocimiento 4.0 Internacional (CC BY 4.0): https://creativecommons.org/licenses/by/4.0/deed.es_ES

C2022 Javier Arias Madero, María José Pizarro Juanas, Joaquín Ibáñez Montoya, Frank Marcano Requena

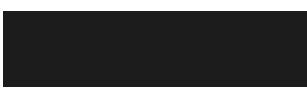




\section{Introducción}

La Escuela de Arquitectura y Diseño de Valparaíso conceptualiza sus proyectos fuera del paisaje exterior con una voluntad de exclusión del entorno inmediato: "La arquitectura desarrollada en Ciudad Abierta fue una arquitectura sin previos, es decir, sin contextos que la hicieran enmarcarse" (Millán, 2019, p.111). Dicha autoexclusión del paisaje lleva a la necesidad de afirmación e identificación del espacio construido con un marco más amplio, de dimensión continental. La necesidad intelectual de comprender la complejidad y diversidad del territorio de América es parte esencial de la condición propia del ser americano. Los colores de la luz natural intervenidos arquitectónicamente tienen el potencial de trasladar esa territorialidad a un espacio cuya visión tiene orientación preferentemente vertical. La investigación pone en evidencia el diseño de mecanismos arquitectónicos que otorgan distintas funciones espaciales a los colores, fomentadas desde una innovadora práctica pedagógica que incide en el estudio de los efectos de la luz sobre lo construido.

La Escuela de Valparaíso tiene su origen en el año 1952. Sus fundadores -entre otros los arquitectos Alberto Cruz, Fabio Cruz, Miguel Eyquiem, Francisco Méndez y José Vial- se agruparon alrededor del Instituto de Arquitectura (1952-1969) desde donde realizaron una práctica profesional al margen de la académica bajo el modelo de los talleres parisinos de Beaux Arts, constituyendo parte del proceso pedagógico de sus alumnos fuera de las aulas. Valparaíso se convirtió "en un laboratorio para sus acciones poéticas como la única manera de vivir (aprender) la arquitectura" (Berríos, 2011, p.54). Los años '70 son la etapa fundacional de Ciudad Abierta situada al borde del Pacífico en Ritoque (Quintero, Chile), campus universitario recreacional destinado para la formación de arquitectos en Valparaíso (Fig.1). Como novedad radical, el sistema de enseñanza de la arquitectura pone en el centro del proceso del diseño la palabra poética como detonador de formas concebidas con gran plasticidad para habitar el espacio.

En 1947 imparten el curso Taller de Composición Pura, de la Facultad de Arquitectura de la Universidad Católica de Chile, Alberto Cruz junto a sus auxiliares Alberto Piwonka Ovalle, Francisco Méndez y Jaime Errázuriz. Trasladado Alberto Cruz a Valparaíso, dictará su primer Curso del Espacio al inicio de la carrera, replicando formalmente los ejercicios del taller que compartía con Piwonka. Sus ejercicios refieren una clara distinción y autonomía de las artes, abandonando el análisis de las cualidades del color de su curso en Santiago, bajo una influencia del arte concreto. 


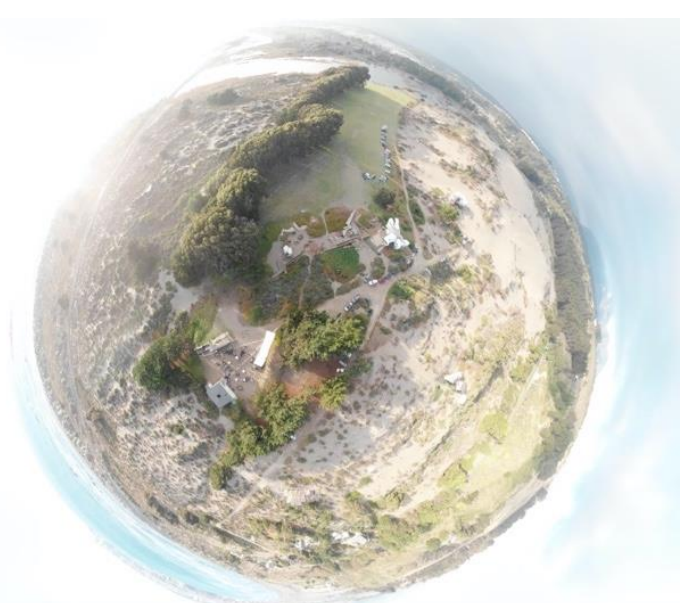

FIG. 1. Ciudad Abierta. Fuente: Extracto de vídeo Guillermos de Manuel, Quintero, 2018

En Ciudad Abierta, profesores y alumnos -en forma colectiva, empírica y especulativa-, simultanean la ideación y construcción de sus edificios. Excluida la planificación del proyecto, se prima el acto de construir, por encima de la calidad del resultado, otra novedad metodológica que modifica la dimensión temporal del proceso proyectual y constructivo. La obra se construye fragmentariamente sin única autoría ni tiempo determinado y por varias disciplinas en un sistema por rondas. Es realizada a golpe de intuición y de manera improvisada con el fin de salvaguardar la capacidad constante de reinvención. Sin un proyecto canónico se construye haciendo, proceso que no excluye la parte reflexiva. Muy al contrario, el hecho plástico como signo residual de una perspectiva poética es resultado de una muy elaborada y continua reflexión del acto de dar forma a la arquitectura centrada en las acciones humanas y una particular manera de habitar el acto como una experiencia territorial. 
Producto de la investigación, se sustenta que la enseñanza de la arquitectura, por parte de la Escuela de Valparaíso - fundamentada en la poesía-, se construye sobre tres paradigmas: i) Ciudad Abierta como laboratorio, ii) la travesía como método, y, iii) el juego y la palabra como instrumentos. Empezando por el lugar, Ciudad Abierta, en un espacio físico de $\mathbf{2 7 5}$ hectáreas donde se imparte desde una visión poética una pedagogía de concepción y materialización de las obras arquitectónicas, lugar para la unidad de convivencia de vida, trabajo y estudio de la Corporación Amereida, como comunidad constituida por un grupo de profesores de la Escuela de Valparaíso. El segundo punto refiere la travesía como táctica académica para refundar poéticamente América desde su expedición, "como un continente con posibilidades propias" (León, 2016, p.7). El proceso de construcción de obras plásticas en sitios muy diversos de la geografía americana (que terminadas se donan gratuitamente a las gentes del lugar) permite acercarse a la realidad de ser americano como una "nueva oportunidad de sacralizar el suelo y los vientos y los horizontes" (Reyes, 2011, p.4). En sentido similar se recorre la ciudad como una experiencia de observación arquitectónica para hacer lecturas espaciales del lugar. El tercer modelo asigna al juego y a la palabra un rol fundamental en el trabajo académico tomándolo como estructura interna para conocer y reconocerse en el mundo. La lectura del territorio se proyecta socialmente otorgando al cuerpo humano límites y escalas vinculadas al contexto del lugar, en cuya "transformación tendrá parte fundante la arquitectura como generadora de contextos creativos normalizados" (Millán, 2019, p.5).

Esta investigación interpreta el color como medio de expresión para una apropiación espacial de la extensión del territorio americano. La observación cromática de la luminosidad de la atmósfera del espacio construido en Ciudad Abierta se confronta con la parte documentaria de cada obra y su representación gráfica como proyecto arquitectónico. El análisis demostrará que la extensión geográfica de América del Sur puede expresarse fenomenológicamente en lo cromático. Como método de diseño está presente de la Escuela de Valparaíso mediante "la adopción del pensamiento fenomenológico en la experiencia, tanto del contexto físico como del vínculo entre la vivienda y los usuarios" (Segre, 2011, p.44). El color como elemento sensorial se pone en valor relacionado con una dimensión territorial. 


\section{Metodología}

La falta de referencias del color en los artículos científicos publicados de la arquitectura de Ciudad Abierta justifica abordar su análisis en los proyectos de la Escuela de Valparaíso. La metodología aplica la experimentación del color en obras construidas en confrontación sistemática con su bibliografía gráfica y documental, analizando los aspectos cromáticos en relación a la luz y el espaciotemporal. Sobre esta base se han seleccionado casos prácticos para el estudio del movimiento del color dentro del espacio, en lapsos temporales concretos y en distintos momentos del día, que se recogen en vídeos y fotografías. El trabajo se complementa con algunas entrevistas personales para contrastar la visión de sus autores o colaboradores ${ }^{1}$.

\section{Fig.2 Esquema de matriz para análisis cromático bajo Modelos docentes y efectos pedagógicos. Fuente: Autor.}

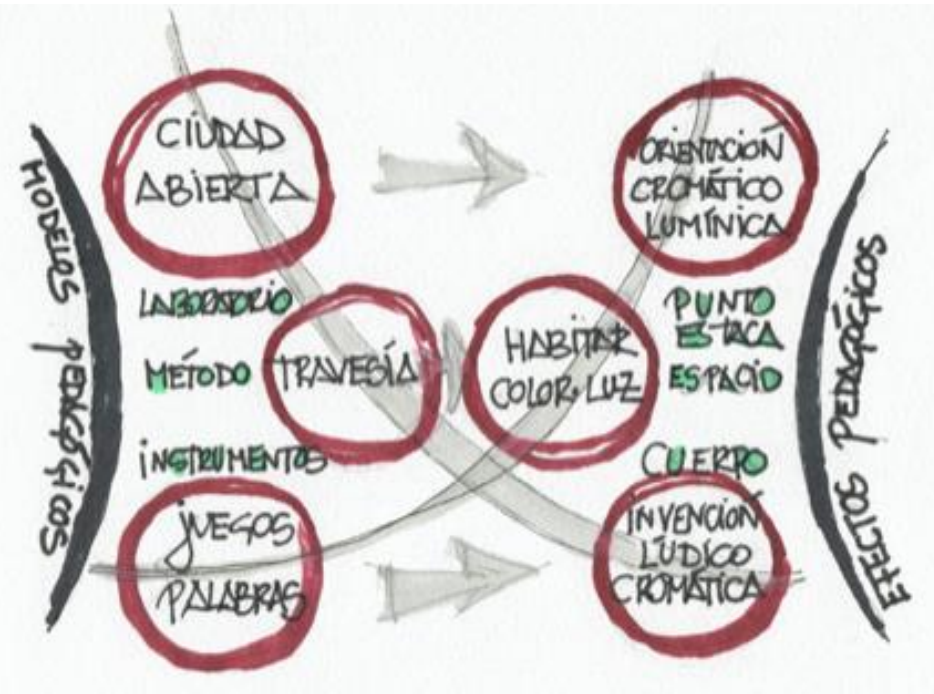

1 La parte teórica de la investigación del color en Ciudad Abierta es producto de un trabajo bibliográfico realizado en el Archivo Histórico José Vial Armstrong con la estimable ayuda del conservador del archivo Adolfo Espinoza, y en las bibliotecas de la Escuela de Arquitectura y Diseño de la Pontificia Universidad Católica Valparaíso y de la Corporación Amereida situada en la Hospedería del Confín. Se indagan las trayectorias de los arquitectos fundadores del Instituto de Arquitectura y del grupo Amereida, así como la influencia de las vanguardias europeas en su docencia del color arquitectónico. Se mantuvieron conversaciones con los arquitectos Miguel Eyquiem, Francisco Méndez y profesores de la Escuela de Arquitectura y Diseño de la Pontificia Universidad de Valparaíso. Una estancia internacional en el año 2018 en la misma Escuela permitió conocer, experimentar y participar en varios de los eventos docentes que se realizaron en Ciudad Abierta. La parte empírica recoge una toma de datos bajo una mirada personal sobre la funcionalidad arquitectónica del color en y con la luz en los espacios de Ciudad Abierta. 


\section{Contexto y ciudad abierta, habitar el límite de la extensión en el color}

¿Qué es la extensión para Ciudad Abierta? De acuerdo con el diccionario de la Real Academia Española la extensión (entre otras acepciones) es "acción y efecto de extender o extenderse" y "medida del espacio ocupado con algo". La Escuela de Valparaíso sintió la necesidad de dar respuesta a las específicas dimensiones del Continente Americano, muy lejos de las medidas eurocéntricas, implicándose holísticamente en un medio diverso, complejo y gigantesco. La extensión se sustancia culturalmente como un territorio para ser habitado, y lo hace de manera muy particular domesticando lo inabarcable, dándole medida y escala.

La palabra del poeta contribuye desde el inicio a la interpretación del lugar, buscando incesantemente ser en la extensión. El proyecto se relaciona en su origen con el lugar, en una apertura del terreno para ser habitado. Se realizan actos entendidos como juegos para reconocer sus límites, como dimensión fundante de las obras. El juego sublima el acontecer de lo simbólico que co-relaciona la identidad y diferencia del hecho existencial. Habitar un eje vertical sin distancias convencionales abre una perspectiva celestial de aprehensión de hechos atmosféricos, inscribiendo la continentalidad en un espacio sin bordes ni distancias. La tarea de los colores es visibilizar lo invisible de los bordes de esa extensión como mecanismo que transmite al espacio interior una lejanía con la que se halla totalmente enfrentada. La arquitectura se sitúa fuera del paisaje: "Sería el despropósito más grande quedarnos allí en el espacio como paisaje" (lommi, 1971, s/p). Mediante la observación arquitectónica de la triada lejanía-distancia-paisaje, durante las travesías se eliminan sus bordes para reconocer el sentido de lo extenso. 
Desde el origen de la Escuela de Valparaíso existe ya gran interés en la exploración metodológica del ámbito de lo invisible. Así se refleja en las reflexiones sobre la relación entre luz y espacio en la memoria del proyecto de la Capilla del Fundo de los Pajaritos y en los estudios sobre la acción del viento del océano Pacífico sobre la cordillera en la propuesta de la Escuela Naval. Se experimenta con la luz, el aire y el viento como condicionantes ecológicos del espacio. Con filtros y espejos se interfiere la luz solar. Mediante tubos sonoros o deflectores se manipula el flujo del viento. Por efecto chimenea y variaciones térmicas se pone en movimiento el aire. Miguel Eyquiem describe el clima de Valparaíso - desde la mirada de un europeo y en una doble analogía atmosférica intercontinental- como una mezcla de aire helado de Suecia y sol ardiente del Sáhara. En los dibujos y acuarelas de la carpeta del taller denominado Chantier 73 se presenta un análisis cromático de la proyección de los rayos solares y orientación de vientos sobre la topografía de los terrenos de Ciudad Abierta. Los bordes se acentúan mediante trazos negros destacando una gradación sucesiva de planos que encierran los límites de "la extensión desplegándose" (Cruz,1982, p.32). Dar visibilidad a lo invisible se constituyó en un postulado que desarrolla una particular visión del color de lo externo (Fig. 3).

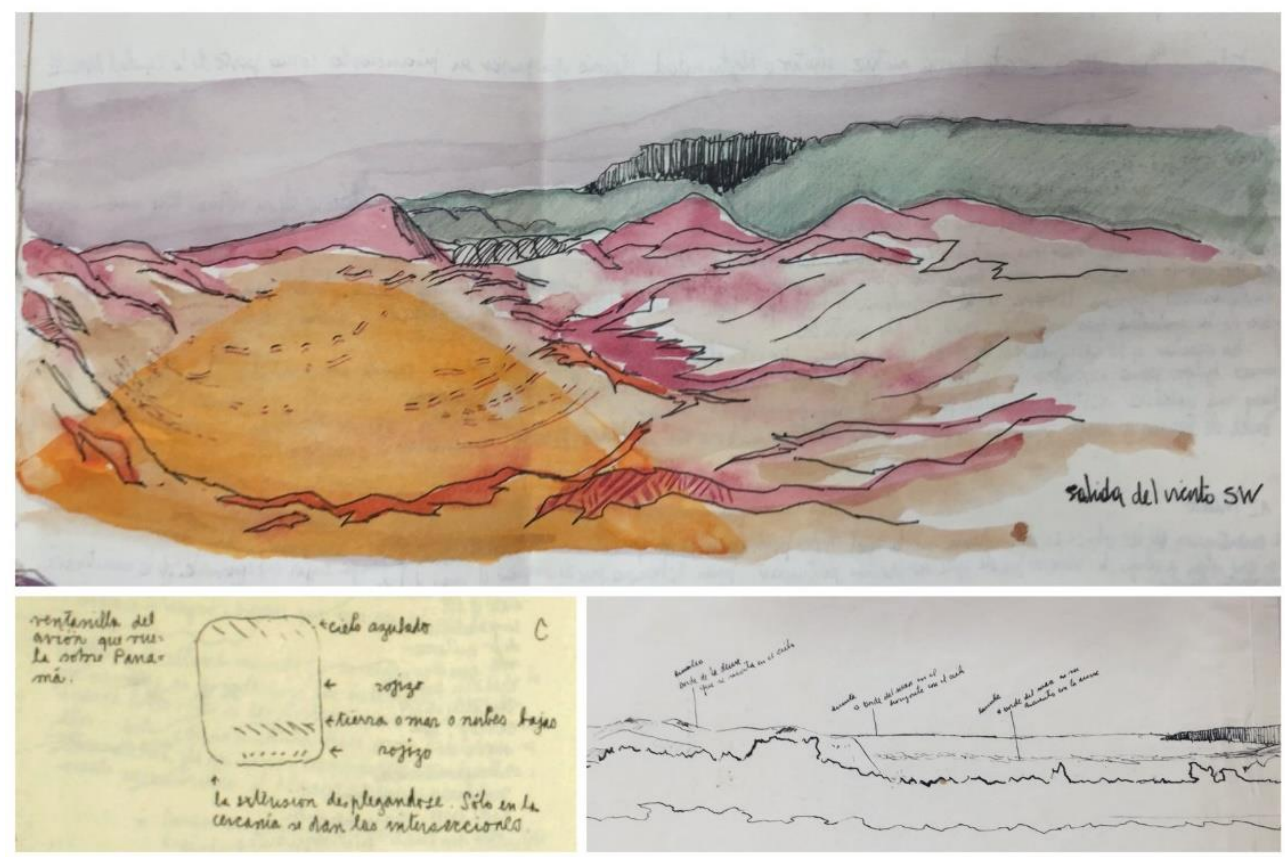

Fig. 3 (a) Acuarela terreno, Hospedería de los motores, 1973. (b) Boceto. (c) Dibujo CAD cha 73 - Chantier Ciudad Abierta, Taller de obras Ronda 4. Fuentes: (a y b) Archivo Histórico José Vial, Escuela de arquitectura, Pontificia Universidad Católica de Valparaíso. (c) Cuatro Talleres de América, 1979, p.32. 
Los colores pasan de tener una función de señalamiento del espacio natural (vulnerables por tanto a la luz y al entorno), para sugerir otro espacio según "un orden determinado por la luz cuando es representada en un teatro cerrado, principalmente esta hace aparecer el lugar $y$ su atmósfera, permite un orden dado por la profundidad que se reconstruye desde la perspectiva" (Garcés, 2015, p.183). Esta disposición, por la cual una cromaticidad lumínica transporta a otro ámbito, constituye una religación espacial que se comparte colectivamente en cuanto que el hombre no es un ser absoluto sino un individuo ligado a los demás. Apertura fundada en un doble mecanismo que vincula al sujeto con el territorio a través de la aprehensión física de los colores de su luz como una construcción inteligible y -por medio de un proceso lúdico de extensión dinámica de su cuerpo- para la asunción espacial de algo en propio (Fig. 4). El sujeto se religa cromáticamente en la luz como espacio en potencia que lo vincula al continente como algo que toma el sentido de una realidad y no la realidad de la cosa dada: "La religación es, pues, una marcha experiencial hacia el fundamento del poder de lo real. Es experiencia fundamental. $Y$ en esta experiencia acontece la concreta intelección de este fundamento" (Zubiri, 2017, p.11). Abrirse a los terrenos es interrogar a la naturaleza sobre su constitución de "ser del límite" (Trías, 1999, p.13) que nos ofrece la experiencia.

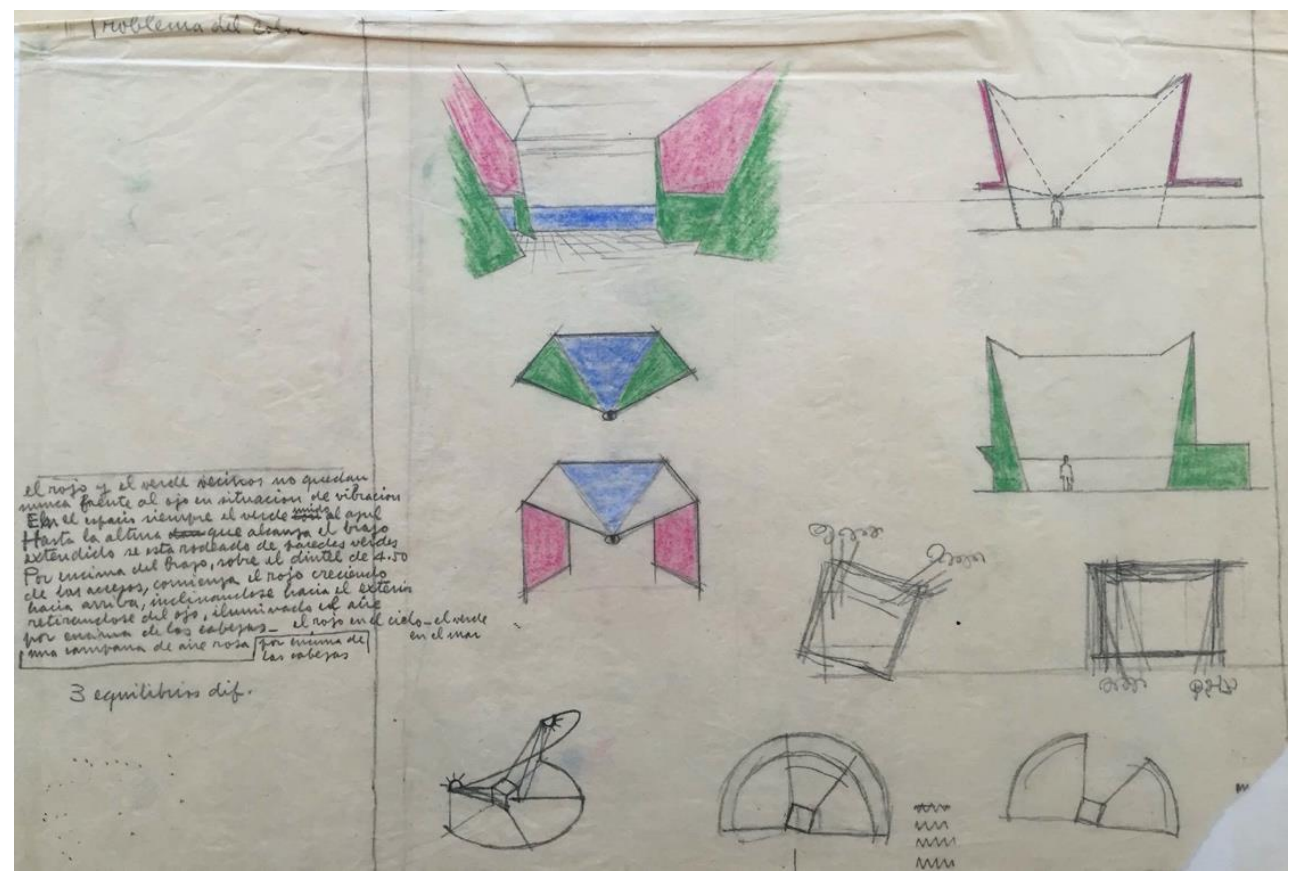

Fig.4 Proyecto Club de Yates, Viña del Mar, s/f. Fuente: Archivo Histórico José Vial, Escuela de arquitectura, Pontificia Universidad Católica de Valparaíso. 
Bajo la pedagogía de la Escuela de Valparaíso el acto de pensar la arquitectura debe llevar a la sensibilidad hacia una relación abstracta e intelectual de observar las cosas sin intermediarios, tomando a los colores como actos externos a la piel arquitectónica. El lugar para habitar pasa de caos a cosmos soñado en una oscuridad en blanco y negro como imagen primigenia. Luego se arma integrado en tonalidades lumínicas como presencia corporal. Contrario al color en la arquitectura, Francisco Méndez, señalará que son los materiales quienes aportan sus propios colores al hecho arquitectónico. Pintar encima de un color es algo externo a lo que es la obra, en arquitectura "encuentro que el blanco no está usado como color sino que está usado por la forma, para que la forma se vea" (Méndez, entrevista personal, 20 julio 2018). El blanco da tamaños al objeto como artificio arquitectónico. La enseñanza se abre a lo moderno rechazando el empleo del color cultural como algo inútil o sobrevenido, "crean su propio standard y estilo, sin colores locales ni folkrorismos, sólo la forma de la eficiencia" (Girola, 1981, $s / p)$. Sin embargo, el color se utiliza en la representación del proyecto como un recurso gráfico para mostrar una idea conceptual o imagen como muestran algunos trabajos de Fin de Grado de la primera generación de arquitectos (Fig. 5). Cruz, por sus dibujos íntimos, y Méndez, por sus murales y pinturas, son dos grandes coloristas.

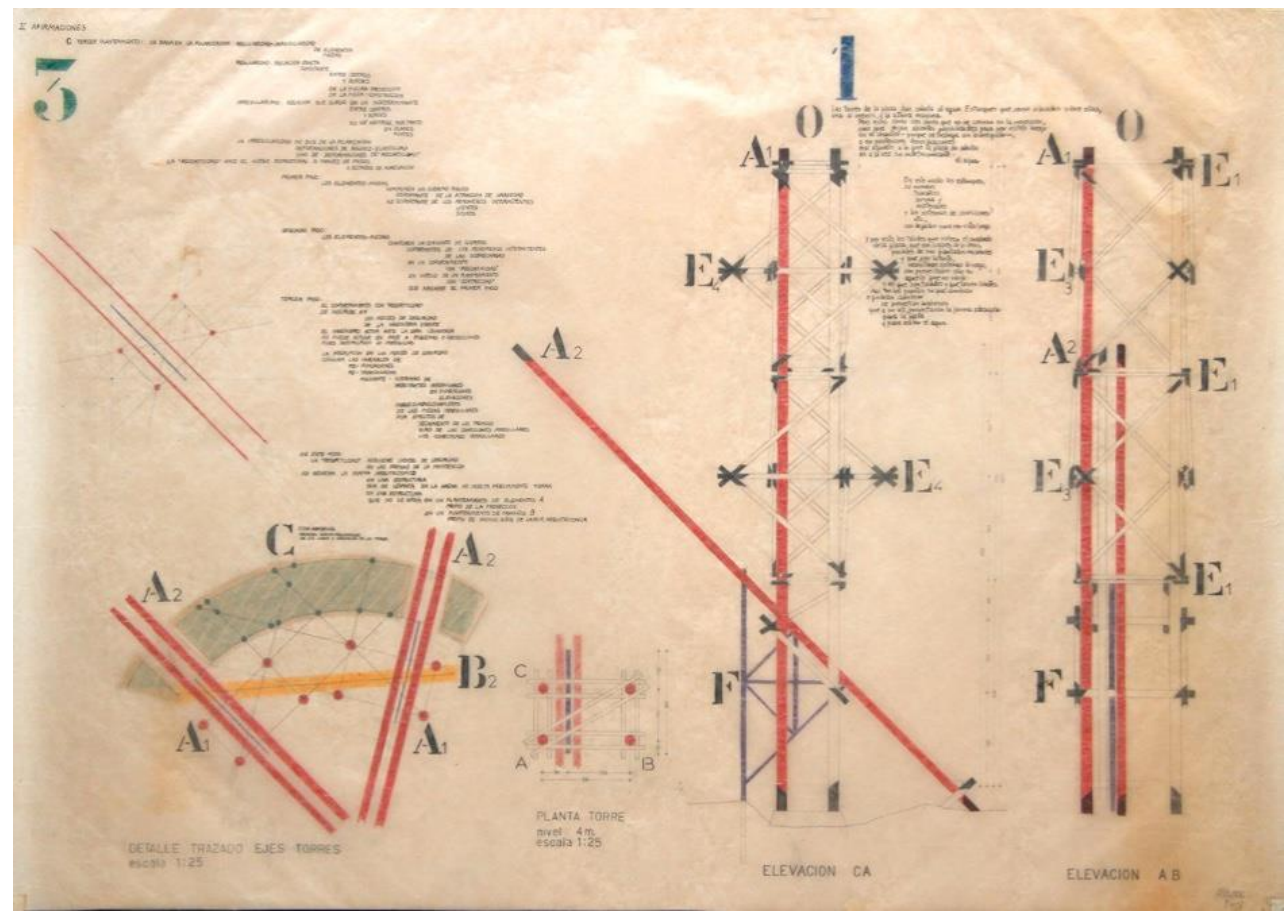

Fig.5 CAO pla 73 - Planimetría Plaza de las Torres del Agua, Isabel Margarita Reyes, 1973. Fuente: Archivo Histórico José Vial, Escuela de arquitectura, Pontificia Universidad Católica de Valparaíso. 
De vuelta de una larga permanencia en Europa, Méndez se dedicó a la pintura, enseñando sobre el color en la Sección de Pintura del recién fundado Instituto de Arte de la Facultad de Arquitectura de la Pontificia Universidad Católica de Valparaíso. Sobre su doble condición de arquitecto pintor afirmaba: "una cosa como si tuviera partido el cerebro no más, sin ningún esfuerzo, me meto en la arquitectura y me olvido de la pintura, me meto en la pintura y me olvido de la arquitectura"(Méndez, entrevista personal, 20 julio 2018). El Curso de murales lo imparte en Valparaíso, entre los años 1969-1973, con la idea de experimentar fuera de las aulas tomando la ciudad como un laboratorio, antecedente del Museo a Cielo Abierto realizado en los años 1990-92 bajo su impulso y dirección. Los murales ubicados en muros seleccionados - "en el sentido artístico, la peculiar geografía y arquitectura de la ciudad permitían enfrentar la pintura con el espacio urbano" (Dardel-Coronado, 2019, p.562) - son puntos de referencias urbanos de vivos e intensos colores pictóricos cuya única función es estar allí señalando únicamente un lugar sin integración diluida en un entorno urbano o natural. Una mirada divagante establece una correlación entre el espacio urbano señalado por los propios colores y aquel que suscita el juego compositivo de sus formas cromáticas en un "doble vínculo que va y viene del espacio natural en que el color "señala», el de un espacio en que el color, como "presencia», establece un llamado a otro espacio, aquel que queremos sugerir propiamente "americano"" (Méndez, 1981, s/p). En línea similar, utilizará los abigarrados colores de sus murales de la escalera de la quebrada de Ciudad Abierta para trasladar una imagen personal de la extensión, como anuncio de una fiesta (Fig. 6).
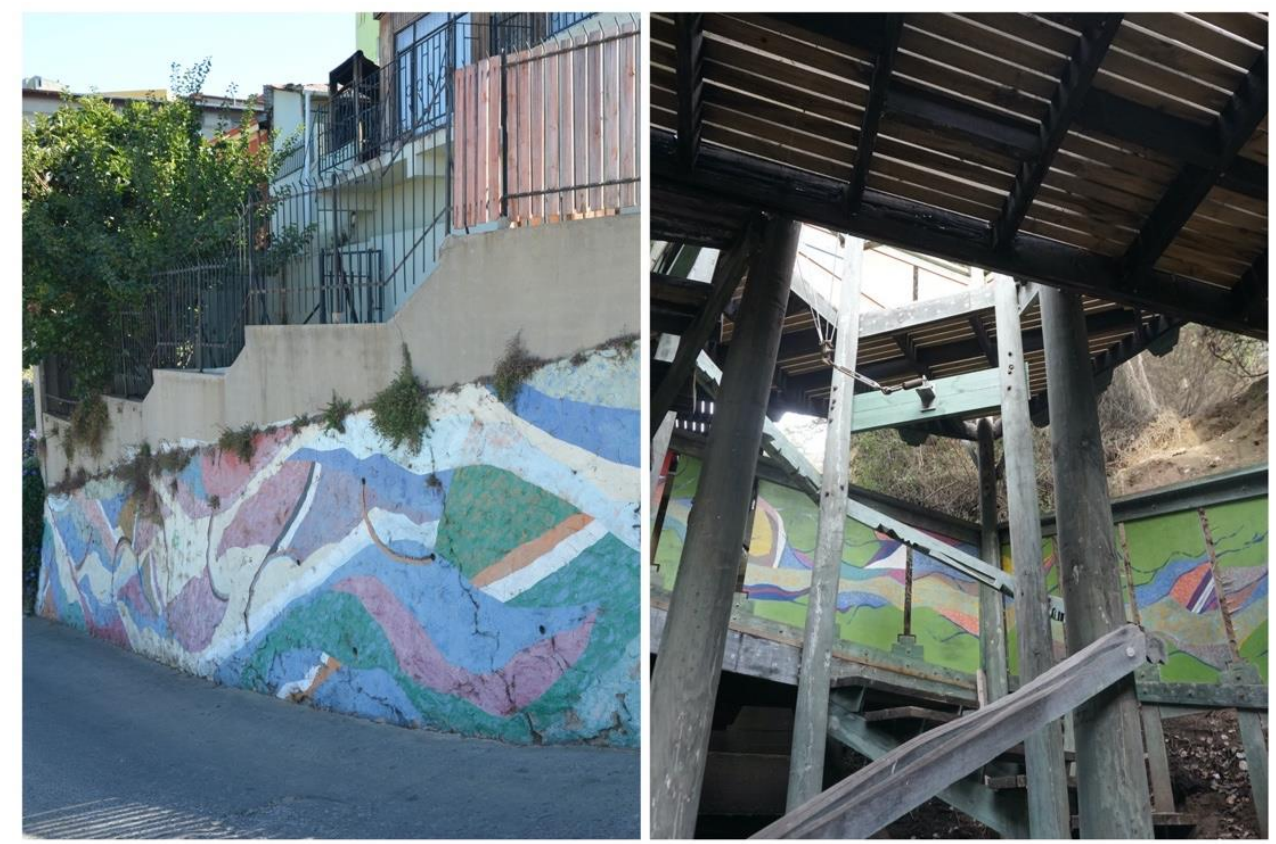

Fig. 6 (a) Fragmento del mural no13 de Francisco Méndez Labbé, bajada calle Rudolph a Ferrari, Cerro Bella Vista, Museo Cielo Abierto de Valparaíso. (b) Murales de Méndez escalera bajada quebrada, Ciudad Abierta. Fuentes: (a) Foto autor, Valparaíso, 2014. (b) Foto Guillermo de Manuel, Quintero, 2018. 
La extensión se presenta ante nosotros como una grandeza o manifestación espacial de lo sublime de la naturaleza que se aprehende como una irrupción o salto hacia algo desconocido, que nos sitúa como espectadores de algo inabarcable. Un movimiento sin dirección hacia el infinito que deja al cuerpo inmóvil en su propia lugaridad, como denominará Méndez a una mirada centrada hacia una diversidad. Ante una vastedad en permanente tránsito los colores tienen luz propia, con independencia de la luminosidad ambiente. Los colores luminosos del lugar se trasladan a las obras como una única realidad dialogante. Durante el oscurecimiento de lo externo, la grandeza comparece ante la memoria como una imagen visual de una luminosidad de fragmentos coloreados donde los colores se presentan en modo de imagen cromática diáfana: "el color se nos fija entonces no en una ubicación que le da una determinada forma, dimensión y vecinazgo con otros colores, sino en el espacio visible y que se comunica a la interioridad de nuestra visión" (Méndez, 2015, p.34).

La lugaridad evoca una humanización de la extensión continental como terredad: "Estar aquí en la tierra [...]con lo que somos o no somos" (Montejo, 2012, p.27). El paisaje de lo extenso ya fue humanizado en el siglo XIX por Andrés Bello en sus famosas silvas de Alocución a la poesía y La Agricultura de la Zona Tórrida. Este planteamiento pictórico de concebir los colores en tránsito lumínico se incorpora al espacio temporal arquitectónico como un postulado que asume progresivamente la Escuela de Valparaíso. Las primeras reflexiones sobre la luz y el blanco aparecen en la memoria del proyecto de la Capilla del Fundo de los Pajaritos, la condición temporal y geográfica de los colores del rayo solar es descrita en la Sala de Música y más adelante en la Hospedería del Errante se ensaya como campo de abstracción de un cubo solar. La extensión se aprehende cromáticamente habitando en la luz, que traslada un sentido de lo inabarcable del lugar a la caja volumétrica, tomando escala humana como imagen mental de una grandeza coloreada; "El hombre habita en la luz, en blanco y negro y, en colores" (Cruz, 1982, p.30).

La reflexión de Méndez sobre la transitividad cromática como identificación de lo diverso conectará con su Pintura no albergada, curso que impartió en la Escuela de Valparaíso junto al del seminario de Cálculo Pictórico que formaba parte del Taller de América. El soporte de la pintura adquiere irrelevancia forzada por los juegos de colores que sugieren la supresión de sus límites "siendo materia de análisis, en su intento por reconocer una pintura expandida vinculada al entorno" (Dardel-Coronado, 2019, p.42). Los colores saltan fuera del ámbito físico mural como inmersión lumínica que señala un lugar para evocar sensorialmente una continentalidad inasible. 
Esta propuesta de habitar en el color un espacio evocado entra en sintonía contemporánea con manifestaciones artísticas que van más allá del marco arquitectónico, donde el lugar se refugia en atmósferas vinculadas a un entorno. En esa línea explora, Peter Zumthor, la capacidad cromática de la luz puesta sobre lo material (Zumthor, 2006, pp.10-72), Philippe Rahm, la temperatura de los colores en una arquitectura con carácter astronómico y meteorológico (Rahm, 2015, pp.36-41) y, James Turrel, su arte inmersivo en "un homme qui marche" ${ }^{2}$ (Turrel, 2001, p.6). Son espacios que estimulan la percepción emocional como un estado de ánimo atemperado por colores que interactúan con un espectador inmerso en la cualidad cromática de la luz (Fig.7).
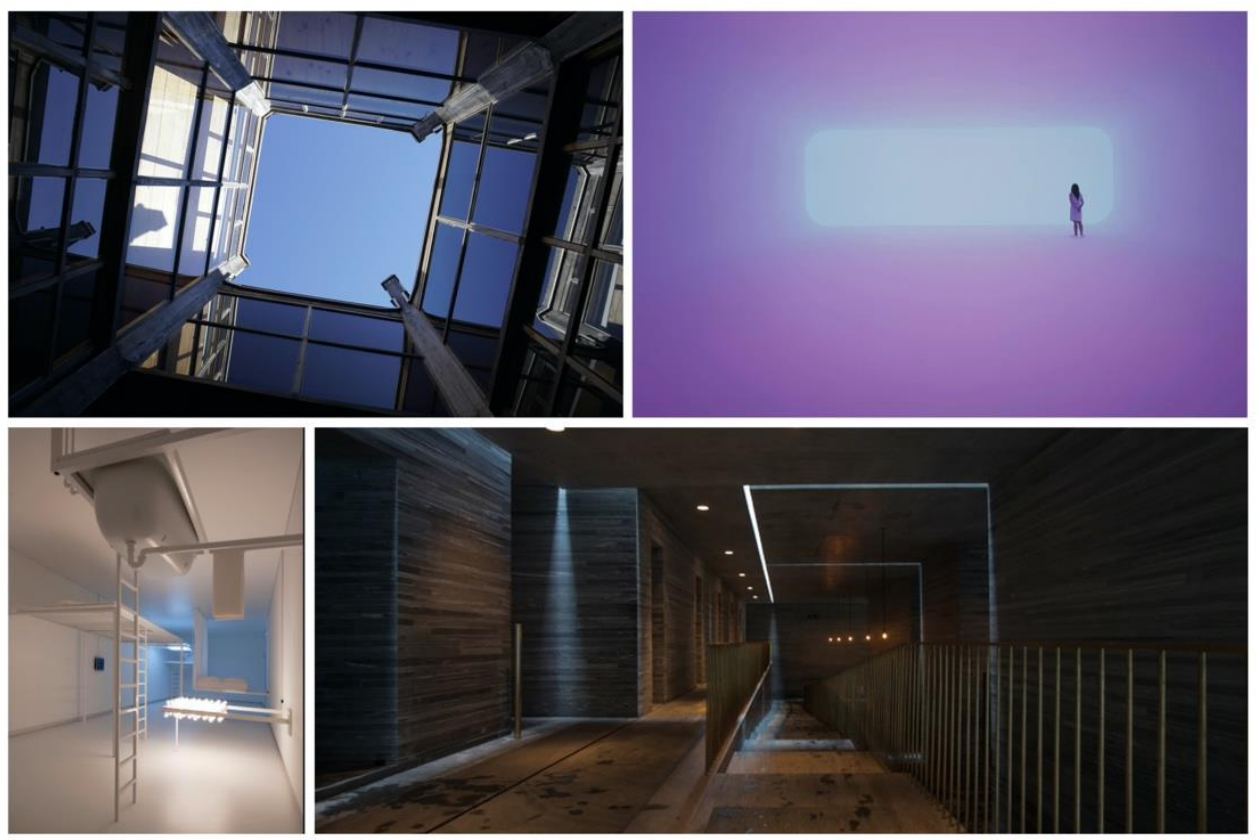

Fig.7 (a) Sala de Música, Alberto Cruz. (b) Breathing Light, James Turrel (c) Habitaciones evaporadas, Philippe Rahm (d) Las Termas de Vals, Peter Zumthor. Fuentes: (a) Foto autor, Quintero, 2018. (b) Foto Florian Holzherr, Los Ángeles County Museum of Art, 2013. (c) Foto Brøndum \& Co, Exposición Louisiana Museum of modern Art en Dinamarca, mayo-sept 2009. (d) Foto Kazunori Fujimoto, Graubunden Canton en Suiza, 1996.

\section{Color en travesía, método de orientación espaciotemporal}

La cuestión vinculada al lugar aparece como leitmotiv entre los miembros de la Escuela de Valparaíso desde su primera travesía de 1965, un viaje iniciático reflejado en dos textos de Amereida. El proyecto de dar forma a la arquitectura - como espacio en el que vivir - en su relación con el exterior tendrá gran relevancia en las enseñanzas que pueden aportar sus expediciones: "más allá del espacio físico recorrido, cubren también otro territorio [...] La tensión entre proximidad y lejanía [...] el estado de estar en casa con el de estar en otra parte [...]entre lo efímero y lo permanente" (Mihalache, 2006, p.25). El planteamiento de enfrentamiento con el paisaje e incorporación de la extensión evolucionará en una propuesta de orientación arquitectónica en horizonte vertical en el ágora fundacional de Ciudad Abierta de 1971.

2 “Un hombre caminando". 
Tradicionalmente las ciudades se constituyen formalmente con orientaciones y distancias, lo que supone optar por un lugar u otro. La descomunal magnitud de la extensión americana precisa de una reinvención del continente. Ciudad Abierta opta como elemento clave para entender esa extensión por una vertical, que se sitúa en un solo punto y sin distancias. La extensión se habita acotada en una orientación en punto estaca ${ }^{3}$ como manifestación de una libertad que queda abierta a lo sin opción. La orientación "no es una ideología, sino la materia propia del arte arquitectónico" (Iommi, 1971, s/p) que abre la posibilidad de alcanzar un modo de habitar humano. En una ciudad sin límites ni distancias el espacio no tiene "una orientación previa para personas y objetos, por eso, puede recibir actos poéticos con su inadivinable orientación" (Cruz, 2016, p.019). El color se constituye en instrumento de orientación en la forma de habitar dicha extensión con "obras destinadas a hacer una lectura sintética del sitio" (Mihalache, 2006, p.25).

En sus clases del Taller de América de 1991 Cruz manifiesta su preocupación por la contribución de los colores para alcanzar una totalidad en la obra, analizando sus relaciones con la pintura y arquitectura de las vanguardias del siglo XX. El color en los movimientos De Stijl y Neoplasticismo fue un elemento eficaz para componer con planos materiales una obra total, cuya abstracción fue plena, homogénea y elemental. Después de los años '30 los colores dejan de construir el orden de una totalidad para teñir superficies que fragmentan la arquitectura. Para alcanzar una unidad artística en la Capilla del Fundo de los Pajaritos el color deja de ser pigmento y aparece como un fenómeno cromático de la luz que se convierte en generatriz del espacio: "Hoy no comparece nada más que la luz" (Cruz, 1954, p.222). El proyecto tendía un acentuado origen místico-religioso de difícil asimilación por la gente del lugar; a juicio de Méndez "la capilla no acogía en absoluto" (Méndez, entrevista personal, 20 julio 2018).

La concepción de Cruz sobre lo cromático arquitectónico, descrita en la memoria de su capilla, ejercería notable influencia en la Escuela de Valparaíso. El color del continente se abandona para situarse en un vacío substanciado en travesía lumínica por medio del movimiento de los colores de la luz (que van y vienen como la arena junto al mar). La cualidad espacial del blanco hará destacar los brillos de las cosas y la espacialidad de los gestos de las manos, trasladando los colores a los objetos y los sujetos. Al tiempo se produce un giro espiritual pictórico en el espacio, que se sacraliza idealizado como una forma única de luz homogénea que genera tamaños a las figuras que contiene; "Es reconocerse en la reivindicación de lo fragmentario y no lo unitario [...] «Liberar el espacio», el vacío es un espacio experimentado y totalmente percibido" (Danés, 2006, p.86). El horizonte de luz indirecta que parte de arriba y se pierde en el interior de Los Pajaritos evoluciona en el proyecto de la Parroquia de Santa Clara de Eyquiem difuminándose por los cuatro costados y el techo, donde los rayos del sol no desvelan su origen "de tal manera que le da un color a la profundidad, un color nuevo que todavía nuestra cabeza no lo ha unido a nuestro cuerpo" (Eyquiem, entrevista personal, 19 julio 2018).

El color físico -en pigmento o vidriado- es aplicado sobre superficies planas para interactuar en un viaje lumínico: a) directamente sobre elementos construidos forzando discontinuidades espaciales, b) bajo la modalidad del huachurado en líneas múltiples, paralelas y coloreadas en finos rayados sobre madera en paredes y techos para crear abstracciones luminosas pintando la

3 El concepto punto estaca es la base fundamental de un partido arquitectónico que elimina las orientaciones horizontales en relación al paisaje, del que se excluye violentamente. 
luz, y, c) empleando la técnica del trencadís en mosaicos de fragmentos cerámicos conformando burbujas cromáticas. Estos modos de aplicación de colores sobre soporte físico tienen el objetivo de hacer vibrar la luz en el espacio para construir horizontes interiores donde se investigan empíricamente magnitudes, cualidades y efectos lumínicos. Los colores adquieren distintas funciones espaciales según el tipo de atmósfera que resulta de los ensayos derivados de una propuesta lumínica concreta.

El uso del color saturado como aplicación física sobre la superficie arquitectónica por la Escuela de Valparaíso es excepcional más allá del propósito lumínico. Un caso paradigmático se dio en las fachadas de la Parroquia de Corral, íntegramente restaurada en 1965 por José Vial como consecuencia del terremoto de Valdivia. Éstas se pintan mediante un juego de colores estableciendo un punto de encuentro simbólico con la geografía del lugar. El tono del barro del suelo y la luz plateada del cielo se relacionan abstractamente integrados en una componente vertical, en un juego de colores que asimila un tránsito de lo terrestre interactuando con lo celeste y viceversa. En esta obra, Vial, aplica por vez primera el huachurado - haciendo vibrar con líneas coloreadas la luz- incorporando una lejanía al espacio interior, técnica que será practica habitual (Fig. 8).

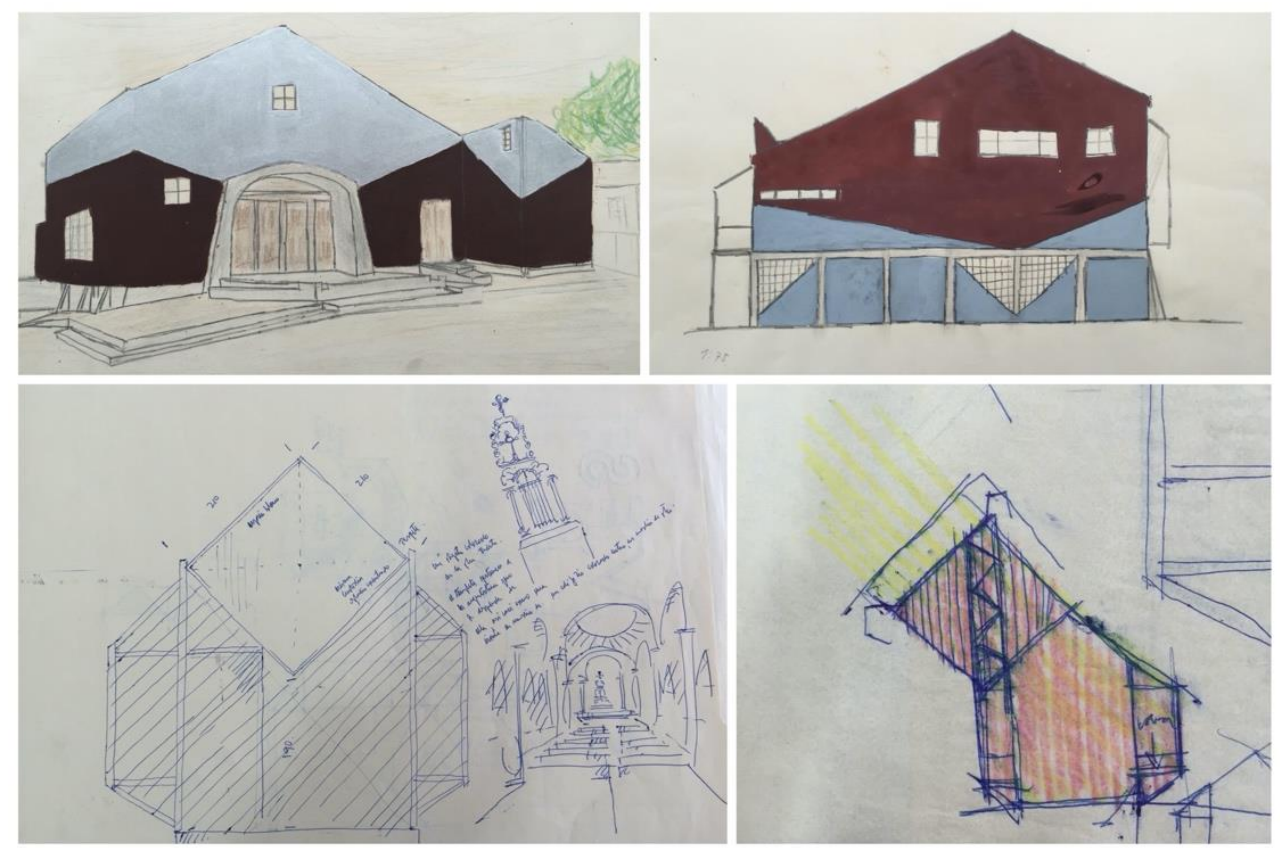

Fig. 8 (a y b) A cor 61 - Parroquia de Corral (pruebas de color), 1961. (c) CAD cha 73 - Chantier Ciudad Abierta, Taller de obras Ronda 5, 1973. (d) CAD cha 73 - Chantier Ciudad Abierta, Taller de obras Carpeta 6, 1973. Fuente: Archivo Histórico José Vial, Escuela de arquitectura, Pontificia Universidad Católica de Valparaíso. 
La Escuela de Valparaíso inscribe los colores saturados plásticamente en signos visuales dentro de la órbita de lo pictórico y gráfico como algo espontáneo, inacabado y evanescente que forma parte de la extensión de un lugar: marcas coloreadas en troncos de árboles junto al Ágora de los huéspedes, trazos coloreados en esculturas de travesías como las de Axis Mundae y Puerto Williams, policromías diversas sobre objetos efímeros realizados en cartón y papel corrugado, etc... Ejercicios cotidianos y artísticos asumidos prioritariamente por pintores y diseñadores gráficos siendo la obra creada un resultado colectivo.

Un primer ejercicio empírico de vinculación lumínica con el entorno geográfico se realiza en 1960 en la Casa en Jean Mermoz del arquitecto Fabio Cruz donde se emplearon vidrios con cuatro colores para revelar una espacialidad de colores muy ligeros y visibles que "crean una estructura de direcciones, profundidades. Colores suaves. No es un espacio coloreado, salvo algún reflejo, un rayo. Son reveladores de espacio" (Cruz, 2015, p.43). Fabio Cruz introduce los colores de la luz de una extensión atmosférica de "resplandores del sol, los colores del mediodía del oriente y el poniente. El gris metálico de los nublados" (Cruz, 2015, p.125).

La escultura de Claudio Girola de la desaparecida Ágora Tronquoy fue la primera obra realizada en Ciudad Abierta (se tienen testimonios únicamente en blanco y negro). El diseñador gráfico José Balcells puso la luz al servicio del color al interponer un material reflectante como el aluminio para establecer un juego cromático entre una cara invisible tintada y otra visible que recibe su reflejo tomando colores. Modo de aparición del color que se sigue replicando en forma de proposición lumínica en la Galería de La Puntilla que utiliza una doble interposición entre elemento reflectante y vidrio tintado mediante unos pequeños espejos exteriores que captan los rayos del poniente para interferir sobre una vidriera coloreada, creando una atmosfera cromática en su interior como aquella de la Casa del entomólogo Luis Peña Guzmán en Colina, ambos proyectos de Eyquiem.

En el interior de la Sala de Música de Cruz resaltan los colores naturales de la luminosidad en movimiento integrados funcionalmente con una luz " "capaz de generar» otras formas" (Cruz, 2016 , p.019). Voluntariamente hermética, constituye una atmósfera de media oscuridad que acentúa un centro espacial lumínico que conecta con lo invisible del paisaje exterior por medio del color de una luz para "«salir» a sus interiores edificados" (Barla \& Cruz, 2018, p.60). La grandeza de la luminosidad del Pacífico y del sol austral penetra en la Sala de música a través de un reducido patio central secularizando aquella divina e incolora de Los Pajaritos: el blanco de la capilla que da forma a la oración pura y piadosa de Alberto Cruz es ahora el azul celeste de la "oscuridad mística de lo desconocido" (Cage, 2001, p.60). El único protagonista de esta sala para la audición musical (sin espacio escénico) es un pozo de luz: columna que matiza, difumina y pone en movimiento al aire y la luz (Fig. 9). Las proporciones de su diseño y su situación de centralidad espacial facilita la circulación del aire por efecto chimenea suspendiendo el polvo que refleja y modula la luz transformándola en sustancia densa, física y espaciotemporal ${ }^{4}$. Sin previos cálculos lumínicos, el rayo solar construye las escalas cromáticas del espesor habitable con fuerte sentido geográfico y simbólico del lugar:

4 https://youtu.be/xivhuihiQLc 
"Rayo de sol anaranjado de la mañana. Luz fugaz cambiante. / Rayo de sol amarillo del medio día. Luz fugaz. / Luz polarizada del cielo azulada monocromática constante durante el día. / Rayo de sol rojo y templado del atardecer luz fugaz y cambiante que se agota en el recorrido. La luz del rayo de sol construye el tamaño" (Cruz, 2016, p.019).
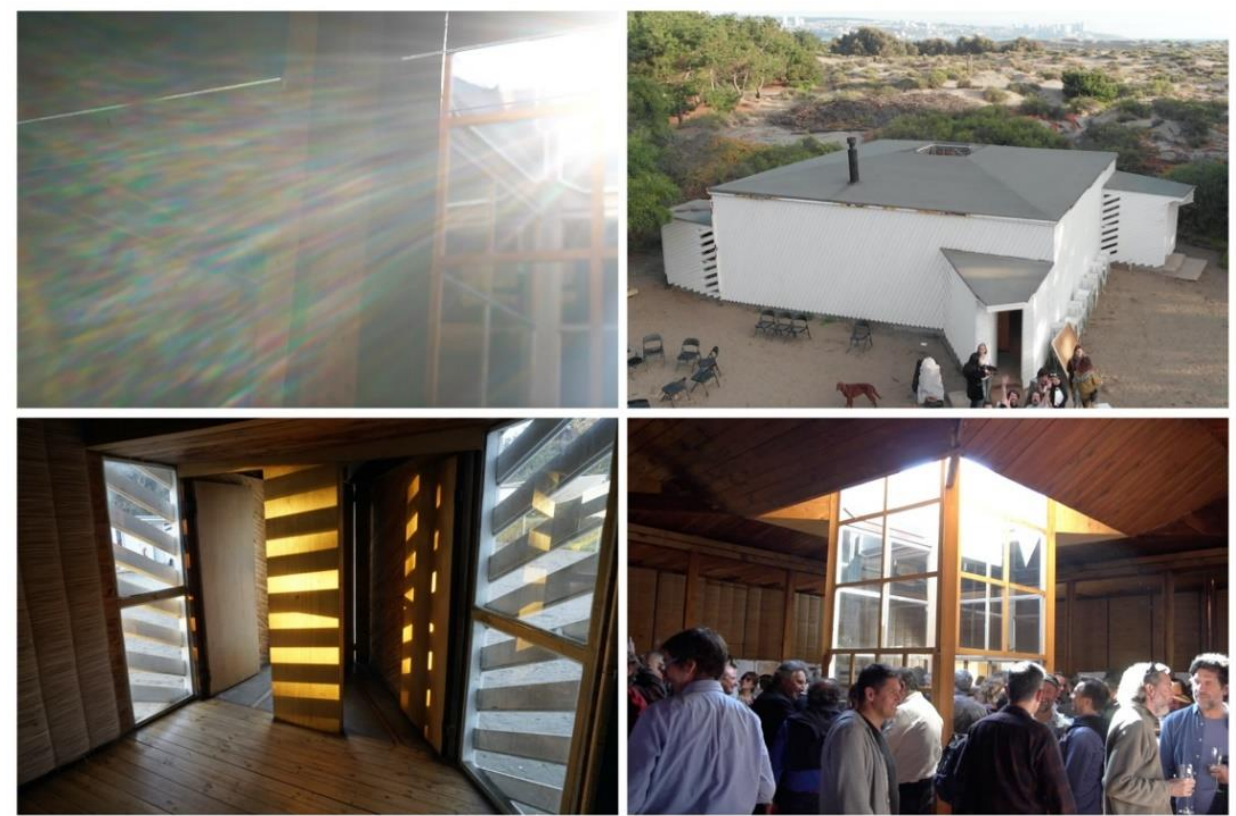

Fig. 9 (a, b, y c) Sala de música. (d) Sala de Música, Acto de encuentro 14 julio 2018 ex alumnos generaciones 1982 a 1988 Escuela de Arquitectura Fuente: Extractos de vídeos y fotos de Guillermo de Manuel, Quintero, 2018.

La Hospedería del Errante es un experimento pedagógico que se concibe como una obra en proceso donde se aplican técnicas propias del mundo de la ingeniería aeronáutica y naval para manejar factores climáticos: "La configuración total de la obra será el resultado de la conformación de cada uno de los elementos con respecto a las condiciones de luminosidad e intemperie asociadas a los puntos cardinales" (Millán, 2019, 113). Su envolvente es un modelo de ensayos para manipular lo invisible de la luz, el aire y el viento. Configurada en intrincadas geometrías aplicadas a los cerramientos exteriores, Manuel Casanueva pone a prueba la teoría del cubo solar de su Tesis del arquitecto orfebre. La memoria del proyecto refiere a una renovación de la tradición mudéjar y mozárabe del mediterráneo por medio de celosías como arreglos seriales para controlar la cantidad y cualidad luminosa del interior. Los rayos solares se ordenan y filtran en la temperie interior interceptándolos mediante vidrios tintados que colorean atmósferas y alumbran puntos muertos 5 . El color como material tintado o látex se aplica sobre ciertos elementos constructivos (en composiciones murales, sobre la madera de arbotantes o en mosaicos) para interactuar con la luz formando en el espacio burbujas cromáticas (Fig. 10).

5 https://youtu.be/6QkkhNU3LCE 
De acuerdo a la orientación que toma el rayo solar interfiriendo un volumen cúbico, Casanueva clasifica la luz asignándole colores según los cuatro cuadrantes identificando coordenadas geográficas con respuestas cromáticas. El espacio contenido se analiza como un cuerpo libre sobre el que actúa un diagrama de fuerzas de luz coloreada con carácter fenomenológico y ecológico. Cada punto cardinal expresa con colores la extensión territorial propia de su orientación. Esta cosmovisión es propia de la noción del punto estaca que habita la orientación lumínica, única y específica del punto que ocupa en el territorio. En el espacio interior la extensión es cualificada por rangos de penumbra, atemperada gradualmente en intensidades según el movimiento oscilante del sol. El cromatismo es consecuencia de proyectar la interferencia del rayo solar con criterios geográficos: "La sombra iluminada, no es más el sur como invierno (lado invernal), lo que traducido a cualificación cromática, es la alquimia del Orfebre, la instauración del amarillo en el cuadrante sur". (Casanueva, 2003, p.80). Cada cuadrante es temperado cromáticamente por la combinatoria de tres factores -orientación, color natural y su permutación - de manera que el norte es amarillo y permuta en azul, el sur es azul y permuta en amarillo, el este es blanco-negro y permuta en una casuística y el oeste es rojo y permuta en azul.
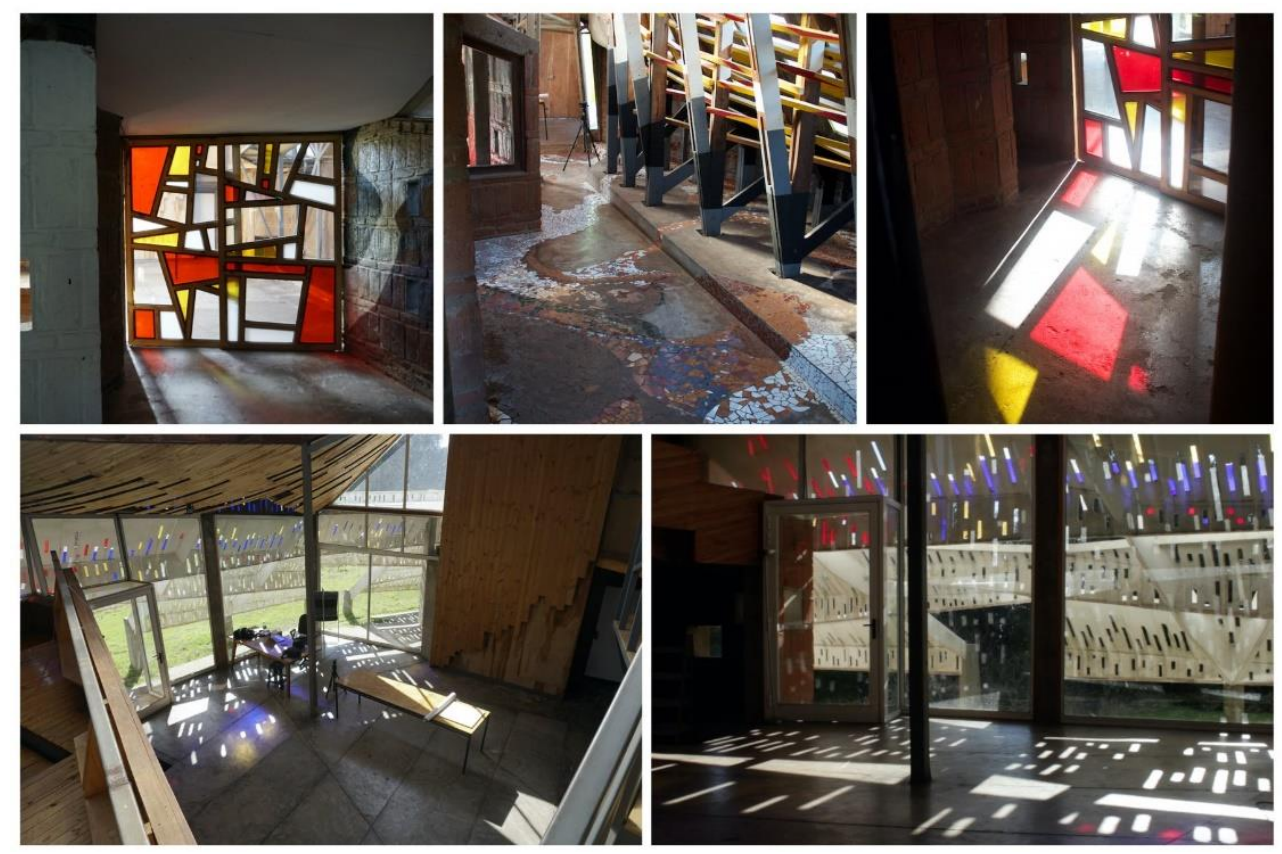

Fig. 10. Hospedería del Errante. Fuente: Extractos de vídeos y fotos de Guillermo de Manuel, Quintero, 2018. 
Situados en el exterior, las sensaciones lumínicas traen colores que se perciben en travesía ecológica: "More accurately understood as the result of complex interactions between physical light in the environment and our visual nervous systems" ${ }^{\prime \prime}$ (Palmer, 1999, p.95). En esta latitud - cuya luz intensa elimina el color del mediodía- la extensión natural se manifiesta sobre las superficies arquitectónicas por efecto de la proyección del rayo coloreado en los primeros y postreros momentos del día ${ }^{7}$. Cruz le dedica especial atención al fenómeno natural de la coloración lumínica: "Así en lo atenuado del alba - preparación a la llegada del color y la aurora, la llegada del mismo-; en lo atenuado del ocaso - despedida del color- el blanco y negro, parece que va a ser ahogado" (Cruz, 1982, p.30). En la inmediata salida del sol aparece la luz blanca con una casuística de sombras largas y negras, luego entra el rayo solar amarillo cálida y paulatinamente sobre las texturas artesanales de los ladrillos del Palacio del alba y del ocaso, solo en sus últimos instantes se multiplican los rojos arcillosos (Fig. 11). A su vez, la disposición arquitectónica en muros semicirculares permite variaciones cromáticas construidas por una intensa vibración lumínica: "a partir - entonces de todos los colores de la visibilidad- que es partir implacablemente de lo múltiple para llegar a lo único, a cada color. Colores construyéndose" (Cruz, 1982, p.31).
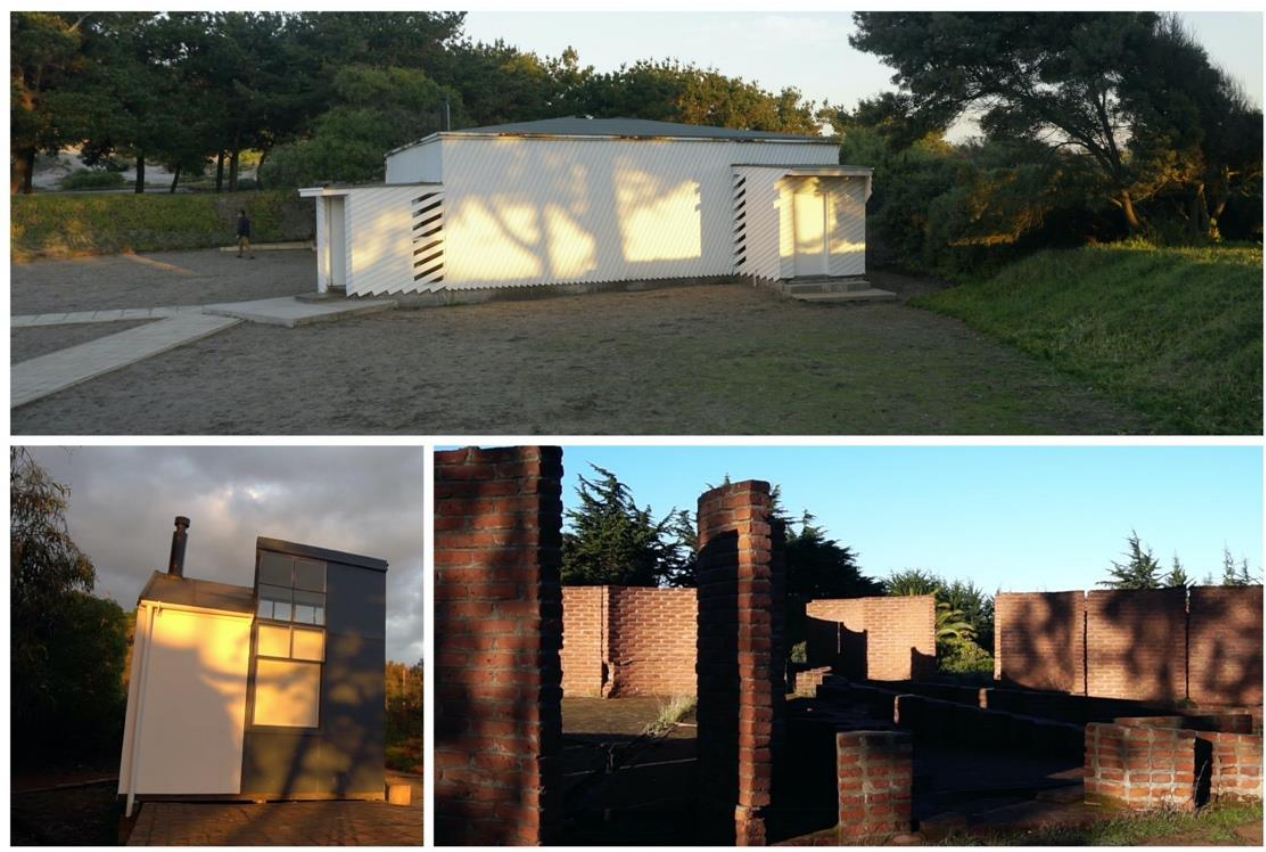

Fig. 11 (a) Sala de música. (b) Cubícula del poeta. (c) Palacio del Alba y del Ocaso. Fuente: Fotos del autor, Quintero, 2018.

6 "Entendido con mayor precisión como el resultado de interacciones complejas entre la luz física en el medio ambiente y nuestro sistema nervioso visual". 7 https://youtu.be/JQViqeTJSLY 
La dimensión temporal construye climas de color en la obra del Cementerio, capilla y anfiteatro, favorecida por su implantación topográfica en hendidura de quebrada, que dilatan indefinidamente el acto de construcción cromática del medio ambiente. Los colores de los materiales constructivos se van transformando en un proceso de alquimia con la vegetación sometida al ciclo de aparición y desaparición - tomando una función espacial como evento plástico. Ladrillos y maderas se muestran cromáticamente en una dialéctica de brotes de vida en época de floración y de lenta muerte por erosión climática a merced del paso de las estaciones: "es una obra que evoluciona, muta a lo largo de los años y reacciona ante los ciclos naturales y cambiantes de las estaciones expresando, mostrando, "dando a ver», revelando diferentes aspectos según sea la estación del año" (Quintanilla, 2015, p.28). Se habita una esfera de naturaleza recreada con pasos de arquitectura, escultura y paisaje en una orientación vertical que "indica hasta que punto sus constructores se decidieron por mantener el arriba y abajo" (Vega, 2015, p.5) donde los fondos naturales intervienen como fronteras de un interior vertical que encierra una extensión espacial al aire libre para la contemplación ${ }^{8}$.

La condición adverbial de estar coloreando es una travesía basada en la luz y el espacio, como representación de una inmersión sensorial tiene su origen en las pinturas de Lascaux. Su andadura continúa con la experiencia estética de las vidrieras góticas, la reinvención del arte medioambiental de los años 60' y las cromosaturaciones y transcromías (Cruz-Díez, 2009, pp.128-143) de Carlos Cruz-Díez que iluminaron el Pabellón francés de la Exposición Universal de Dubái 2020. El fenómeno natural y temporal de la coloración del espacio asociado a la dinámica de lo vivo ha evolucionado hasta alcanzar la atmósfera cromática radical de los centros de datos, atemporal y sin presencia humana. Mientras los signos cromáticos de las travesías de Ciudad Abierta desaparecen fusionados con el ciclo vital del lugar, el color de las nuevas catedrales de la inteligencia artificial se desvanece codificado en un eterno bosque tecnológico. Un nuevo repertorio de colores artificiales anticipa la fragilidad humana bajo control tecnológico, un urbanismo extremadamente abstracto donde el hombre no termina de encajar (Fig.12).
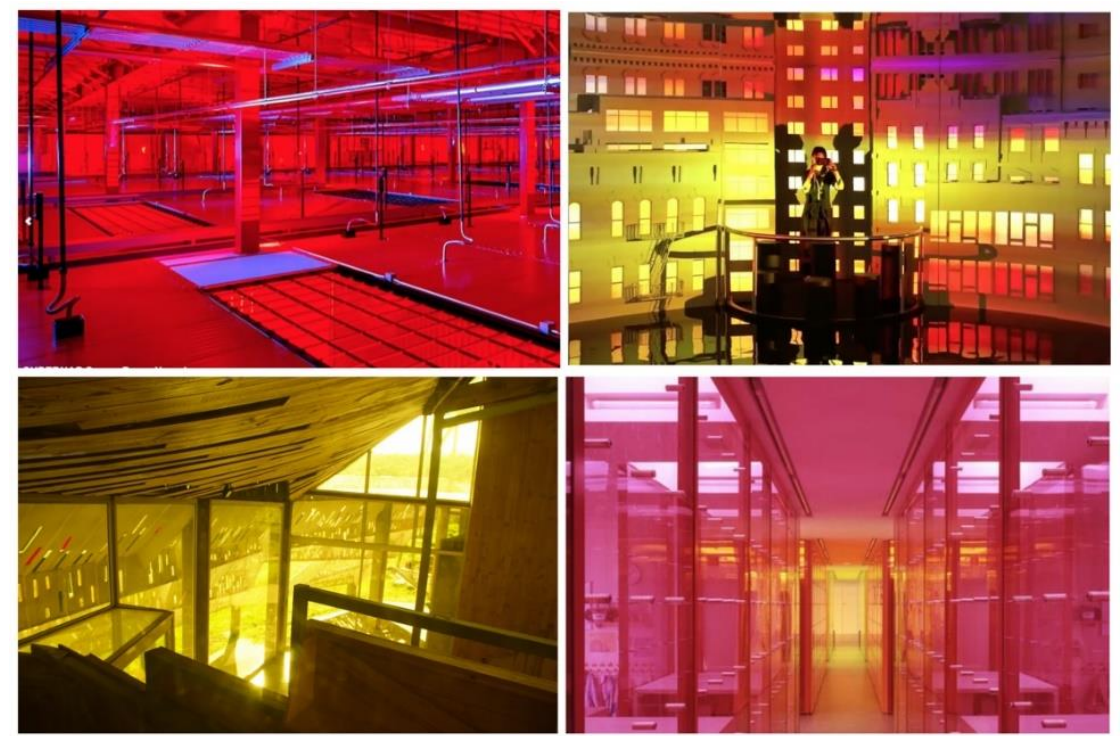

8 https://youtu.be/ZhDgqPXcgL8 
Fig. 12 (a) SUPERNAP Server Farm Nevada, Rem Koolhaas. (b) Instalación cada puerta es una pared, SUPERBLUE (c) Hospedería del Errante, Manuel Casanueva d) Guardería Els Colors, RCR Arquitectes. Fuentes: (a) Extracto Lecture on the countryside, Harvard University Graduate School of Design, 2015. (b) Extracto Exhibición Museo SUPERBLUE, 2021 (c) Foto autor, Quintero, 2018. (d) Foto H. Suzuki, Manlleu en Barcelona, 2004.

\section{La reinvención del espacio de lo cromático a través del juego y la palabra}

El proyecto de arquitectura se estructura como un partido jugado en cuatro actos con el fin de percibir la orientación del entorno y reconocer límites a la obra. Ciudad Abierta abre sus terrenos para ser habitados "armando el lugar" (Luza, 2013, p.23) cuyo acceso se conceptualiza como un recorrido por un pórtico (Fig. 13). La esencia del proyecto debe ser hallada tomando distancia de lo edificado en una especie de régimen nocturno sin la presencia de colores donde "el hombre aparta su vista de lo exterior y la centra en sí mismo" (Kandinsky, 2019, p.48). En el primer acto se habita el cuerpo en obscuridad y sin orientación, para luego extenderlo sobre el lugar para tomar medidas al proyecto. Los tres actos subsiguientes, que ocurren ya en la luz, son una experiencia íntegra donde "entra el cuerpo con todos los sentidos que conforman la cercanía y la lejanía" (Barla \& Cruz, 2018, p.36). La palabra poética asume el rol de orientar al lugar en un punto estaca, liberado de programa funcional o de relaciones visuales con el contexto circundante, para "traer la realidad, lo existente y lo por crear -la obra- a una presentación que lo deja ante ella" (Barla \& Cruz, 2018, p.51). 


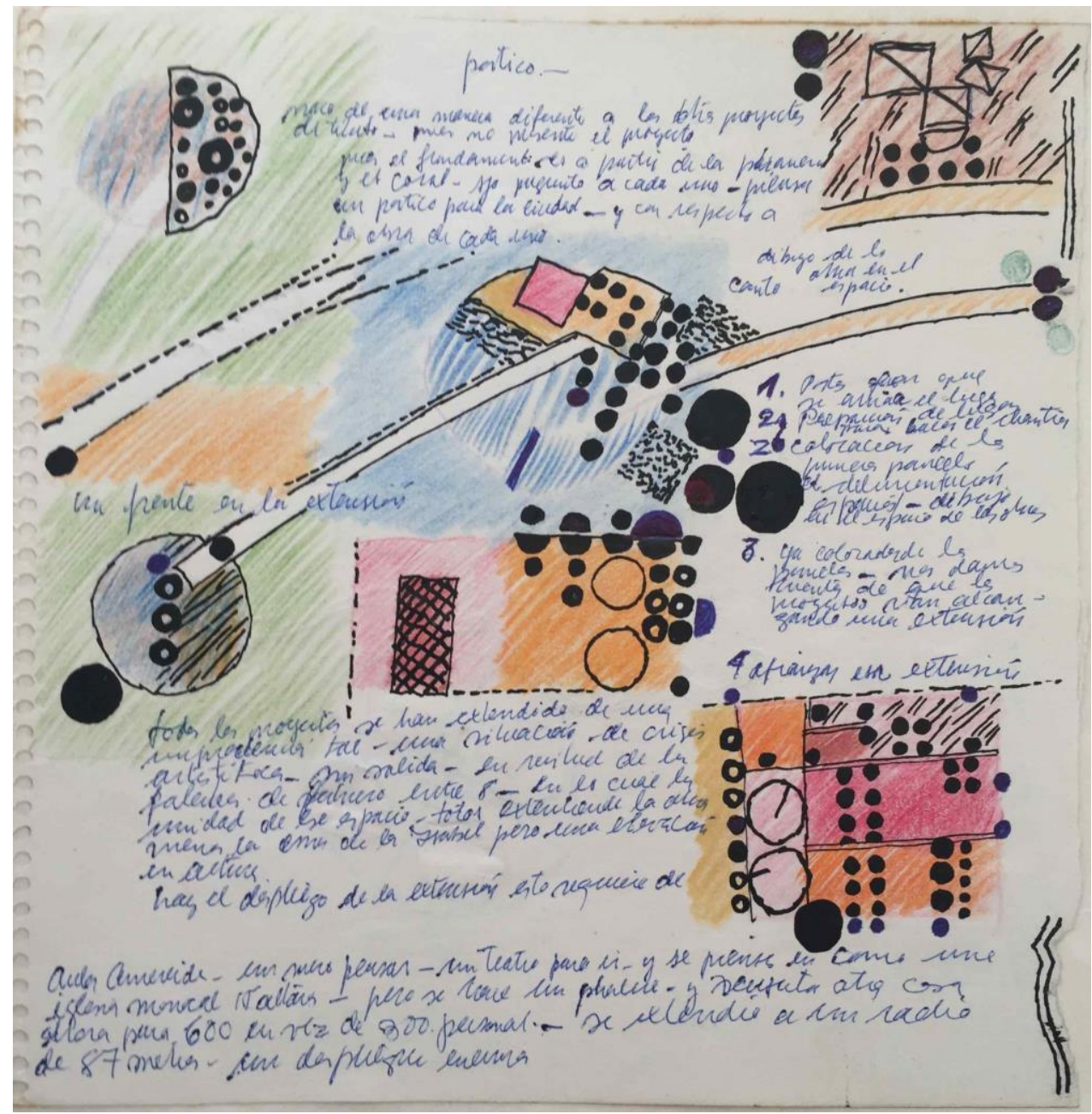

Fig. 13 Proyecto de Pórtico en Ciudad Abierta, 1971-73. Fuente: Archivo Histórico José Vial, Escuela de arquitectura, Pontificia Universidad Católica de Valparaíso.

La acción creativa de la invención del espacio se ejerce bajo un principio de teatralidad con actores, escenario y motivo. Los colores entran en escena como parte del juego teatral donde coexiste un mundo real y sensible que es expresado cromáticamente para estimular la espiritualidad, fantasía e imaginación creativa, con otro de ficción que se autoconstruye mentalmente fomentado por el atrezo:

Un aspecto idiosincrático de las phàlenes de la Escuela son los trajes, máscaras y tocados utilizados con frecuencia en los actos, una indumentaria a medio camino entre una escultura portable y una arquitectura prêt-à-porter, que auxilia mediante el señalamiento del cuerpo, el paso a la dimensión poética (Berríos, 2017, p.19). 
El vestuario de la obra Corazón a gas de Tristán Tzara, que fue dirigida por Méndez, fue diseñado con simples formas geométricas de colores puros en línea con los trajes del Ballet Triádico de Oskar Schlemmer. Las formas asimétricas coloreadas acentuaban sus bordes con el fin de descontextualizar al actor y desfigurar al personaje, otorgando valor propio a las diferentes partes del cuerpo. De igual manera, los alumnos de Casanueva se visten cromática y colectivamente siguiendo la tradición del hombre primitivo para disfrutar lúdicamente en los Torneos y las fiestas (Fig. 14). El Curso de Cultura del Cuerpo imparte un aprendizaje similar al curso preparatorio de la Bauhaus de Weimar de Gertrud Grunow donde el movimiento resulta de la percepción interior espiritual de sonidos y colores: "Su clase se denominaba 'teoría de la armonización' y se basaba en que hay un equilibrio universal arraigado en el ser humano de colores, tonos, sensaciones y formas" (Droste, 2019, p.69).
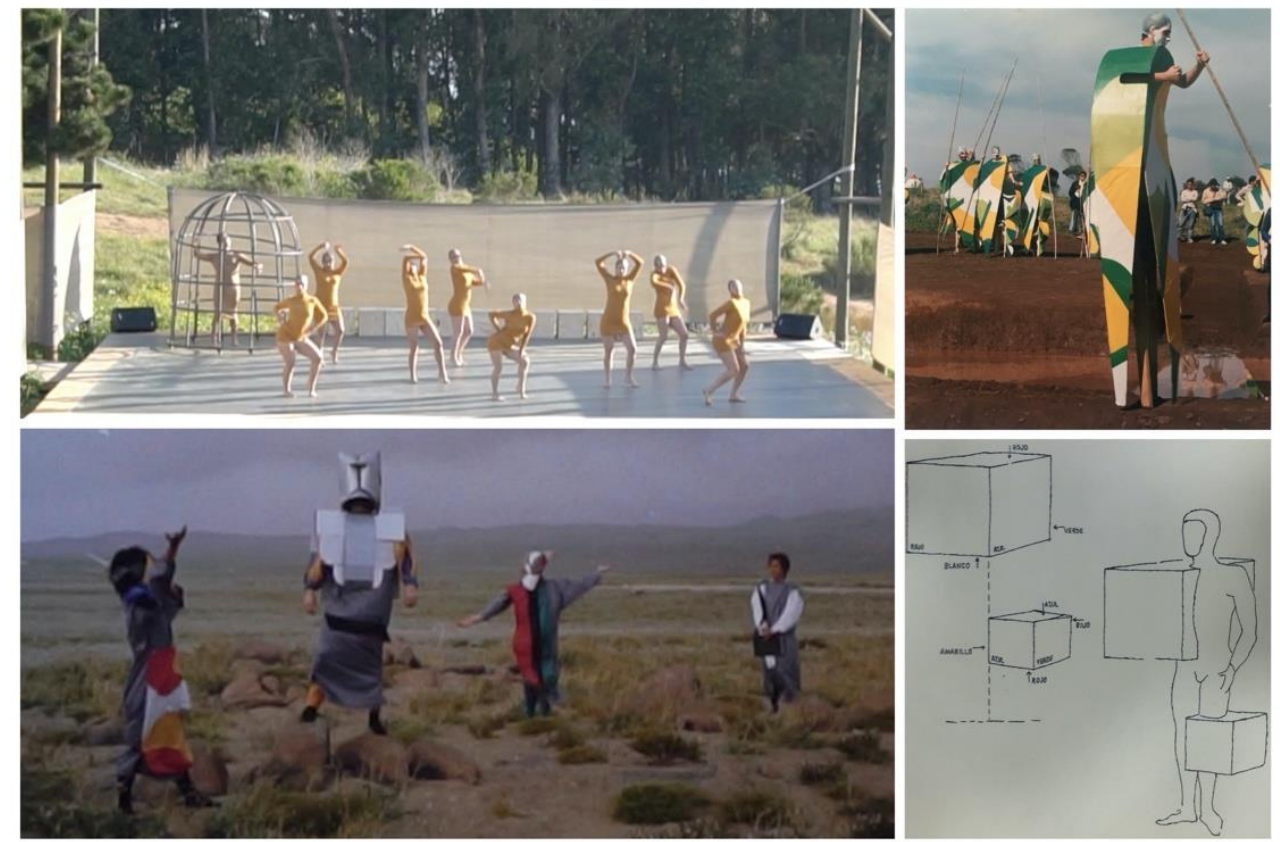

Fig. 14 (a) Obra de teatro en Plaza de la Cruz del Sur en Ciudad Abierta, 6 octubre 2018. (b) Torneo Luodo en Ciudad Abierta, 1984. (c) Acto poético en Caldera, s/f. (d) Diseño de figurín, Carpeta Registro de actividades, viajes, exposiciones y actos públicos de obras del Instituto de Arquitectura. Fuentes: (a) Foto del autor, Quintero, 2018. (b) Donación viuda Manuel Casanueva al Archivo Histórico José Vial. (c) Archivo Francisco Méndez Labbé, Estudio pintor en Santiago. (d) Archivo Histórico José Vial, Escuela de arquitectura, Pontificia Universidad Católica de Valparaíso. 
A través de un ritual y por medio del recurso del movimiento corporal colectivo se alcanza el carácter abstracto de constituirse en extensión con el fin de apropiarse espacialmente del territorio sobre el que se construirá la obra. Así como la liturgia eucarística sacerdotal hace acontecer lo divino, el ritual del poeta advierte el advenimiento arquitectónico a la manera del deambular procesional del sacerdote en un "ir y venir sin contratiempo" (Cruz, 1954, p.229) y mediante "la espacialidad de los gestos, las actitudes, los ornamentos" (Cruz, 1954, p.225). La ceremonia la dirige el profesor (sujeto guía) estableciendo ciertas reglas al alumno (sujeto acción) que se pone en movimiento dinámico tomando tamaños al terreno (escenario) para fijar la posición de la arquitectura (motivo) frente a su medio natural. La Escuela de Valparaíso trata de "recuperar el valor de la experiencia como parte de la experiencia de proyectar la arquitectura" (Luza, 2013, p.14). Vivencia totalizadora, única, temporal e irrepetible para alcanzar un estado de trance con el lugar "en que se vea -sin esfuerzo- más de los bordes de las formas" (Cruz, 2016, p.018).

Para alcanzar el sentido de lugaridad el cuerpo se engalana y significa colectiva y cromáticamente para reconocerse extendido en ese lugar a través de artefactos buscando grados de intimidad con el territorio que ocupa temporalmente. La búsqueda iniciada por la Escuela de Valparaíso de lo sin bordes se traslada a la producción contemporánea de exhibiciones artísticas colectivas de grupos como TeamLab o Superblue que toman temperaturas al medio natural mostrando un espacio en permanente tensión entre interior y exterior (Fig. 15).
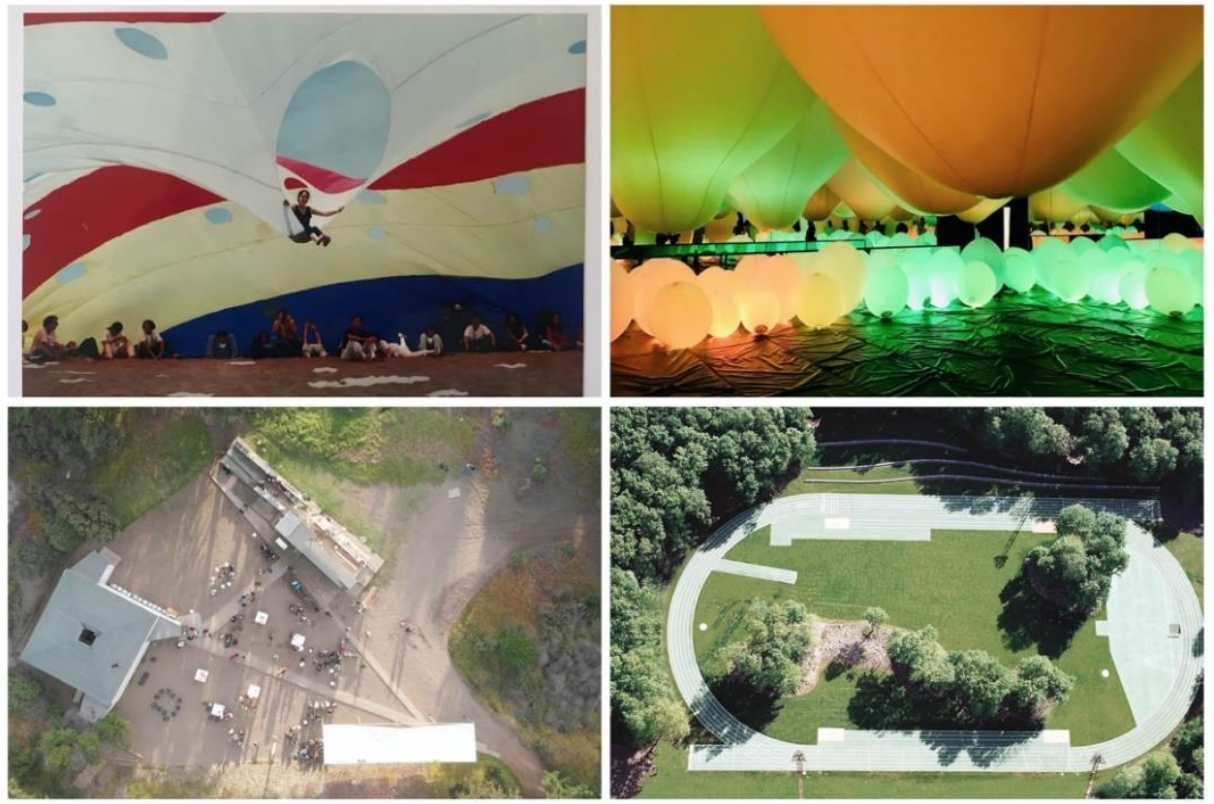

Fig. 15 (a) Membrana aerofuselada, Manuel Casanueva. (b) Instalación arte experimental, Ong Weyjuo. (c) Conjunto Sala de Música, Alberto Cruz. (d) Estadio de atletismo y pabellón 2x1, RCR Arquitectes. Fuente: (a) Donación viuda Manuel Casanueva al Archivo Histórico José Vial. (b) TeamLabBordeless, MORI Building, Odaiba Tokio, feb 2020 (c) Extracto de vídeo de Guillermo de Manuel, Quintero, 2018. (d) Arquitectura Viva Monografías, no93-94, 2002, p.98. 


\section{Conclusiones}

En la Escuela de Valparaíso la acción cromática de la luz se desarrolla a lo largo del movimiento espaciotemporal según estrategias plásticas que asignan a los colores funciones espaciales en un equilibrio entre teoría y praxis real del proyecto. A través del análisis de seis variables matriciales se interrelacionan técnicas de enseñanza y efectos pedagógicos que interpretan los colores en tránsito, flujo de invisibles de una realidad territorial. La terna de modelos docentes está configurada por Ciudad Abierta como campo empírico de ensayos (1), observación en travesía como método aplicado (2) y binomio juego y palabra como mecanismo (3). Los fines de la enseñanza del color son: orientación lumínica del punto estaca (4), habitar el territorio en el color luz (5) y reinvención lúdica de la extensión corporal (6).

Lo continental americano se exterioriza cromáticamente en el punto estaca como una opción que sitúa lo inasible del territorio en el espacio para ser habitado fenomenológicamente orientado por sus colores lumínicos. El alumno se constituye en extensión recreado en un cuerpo de formas geométricas elementales coloreadas incorporado en un espacio ideal y esférico como territorio circunscrito.

Habitar la extensión en el color: La Escuela de Valparaíso visibiliza la luz americana en atmósferas cromáticas como una categoría estética, liberando a los colores del soporte material y de convencionalismos culturales. Se habita funcionalmente el color desde la luz como una práctica pedagógica, y mediante formas eficientes (que se colorean) toman el lugar con el objetivo de vincularlo a otro espacio -imaginado e interiorizado- que refiere a la extensión territorial de América. Al color hay que imaginarlo en silencio como el sonido de una luz que actúa sensorialmente sobre la materia arquitectónica, construyendo las formas y tamaños de la extensión a través del rayo solar. Refiere a otro espacio para ser habitado, aquel propiamente americano sometido por sus puntos cardinales.

Orientación en travesía cromática: La orientación cosmológica en un punto estaca supone un enfrentamiento radical con el paisaje, donde el proyecto arquitectónico no toma imagen del entorno. La orientación en horizonte vertical genera un espacio autárquico habitado por los colores de la luz gobernado por un eje cosmológico tierra-cielo que toma constante medida a la extensión del territorio. Cambia el territorio, cambia la luz, cambia el color, cambia el espaciotemporal. La Escuela de Valparaíso asigna a la luz forma plena y total, medio que hará presente con sus colores inmateriales el contexto americano en una lógica temporal de poiesis. La extensión entra en la arquitectura durante un proceso de exteriorización de los colores con fuerte carácter adverbial (tranzados al verbo colorear) que se perciben inteligiblemente en interacción ecológica con el medio territorial. 
El color como instrumento del juego creativo: La acción de extenderse en el espacio durante el juego es construir una relación del cuerpo con el entorno para reconocerse modificándolo. Es una pedagogía que construye mentalmente una ficción del mundo real y sensible a través de la evolución de un juego estimulado cromáticamente. El color es un mecanismo de seducción en la acción corporal del alumno en relación con un territorio al que quiere darle medida, dimensión y escala humana. Contribuye al partido arquitectónico como un componente de una corporiedad artificial puesta en tensión con fuerzas naturales como el viento y la gravedad. Lo lúdico se agiganta cromáticamente a través de un orden, tan normado como libre, para aprehender la diversidad territorial de América.

El color en Ciudad Abierta es el hilo de Ariadna mediante el cual el hombre emerge de la caverna a la luz, iluminado por los colores accede a su más alto nivel creativo.

\section{Referencias}

ASENSIO, C., BENDITO, F., CABAÑAS, N., DANÉS, D. et al. Aproximación del hombre al paisaje a través de rostros y máscaras en Las piedras de San Agustín, Sobre la estatuaria Megalítica de Jorge Oteiza. Madrid: Departamento de Proyectos Arquitectónicos de la Universidad Politécnica de Madrid - Mairea Libros, 2006. ISBN 10: 84-9352786-6 y ISBN 13: 978-84-935278-6-0.

BAIXAS, J., CÁRAVES, P., PURCELL, JUAN, QUINTANILLA, J. y VEGA, A. En lugares de Mínima Huellas. Una mirada al cementerio de Ciudad Abierta. Santiago de Chile: Editor José Quintanilla. Catálogo Exposición Casona de Campus Lo Contador Universidad Católica de Chile, 2015.

BARLA, B., CRUZ, A. Amereida-Palladio, carta a los arquitectos europeos. Valparaíso: e(ad) Ediciones. Escuela de Arquitectura y Diseño Pontificia Universidad Católica de Valparaíso, 2018. Segunda edición ISBN: 978-956-170357-5.

BERRÍOS, M., BROWNE, S., CRUZ, A., LAFUENTE, P. Y PÉREZ, F. Alberto Cruz, El cuerpo del arquitecto no es el de un solo hombre. Santiago de Chile: Fundación Alberto Cruz Covarrubias, 2017. ISBN: 978- 956-09035-0-1.

BERRÍOS, M. Tácticas de invisibilidad, arquitectura, juego y desaparición. Sao Paolo: Lisette Lagnado (ed), 2011.

CAGE, J. Color y cultura. Madrid: Ediciones Siruela, 2001. ISBN: 84-7844-380-0.

CÁRAVES, P., DONOSO, M.E. Y RODRÍGUEZ, E. De la observación a la forma en arquitectura. Valparaíso: e(ad) Ediciones. Escuela de Arquitectura y Diseño Pontificia Universidad Católica de Valparaíso, 2016.

CASANUEVA, M. Libro de Torneos. Valparaíso: Ediciones universitarias de Valparaíso, Pontificia Universidad Católica de Valparaíso, 2009. ISBN: 978-956-17-0451-0.

CASANUEVA, M. De los Campos de Abstracción y los Elementos para una arquitectura experimental. Santiago de Chile: Colorama SA. Facultad de Arquitectura y Diseño Universidad Finis Terrae, 2003. ISBN: 956-299-030-3.

CLAIRIS, C., GIROLA, C., IOMMI, G. Y STRATIGOPOULOU, M. La gracia grecia equivoca la luz. Valparaíso: Talleres de Investigaciones Gráficas de la Escuela de Arquitectura Universidad Católica Valparaíso, 1981.

CRUZ, A., GIROLA, C., IOMMI, G. Y MÉNDEZ, F. Cuatro Talleres de América en 1979. Viña del Mar: Universidad Católica de Valparaíso e Instituto de Arte, 1982.

CRUZ, A. Proyecto para una capilla en el fundo "Los Pajaritos". Valparaíso: Anales de la Universidad Católica de Valparaíso no1, 1954.

CRUZ, F. Casa en Jean Mermoz, carta memoria del año 1960. Valparaíso: Ediciones e(ad). Escuela de Arquitectura y Diseño Pontificia Universidad Católica de Valparaíso, 2015. ISBN: 978-956-8192-07-5.

CRUZ-DÍEZ, C. Reflexión sobre el color. Madrid: Fundación Juan March, 2009. ISBN: 978-84-7075-564-4. 
DARDEL-CORONADO, M. Espacio y paisaje como criterios curatoriales en el museo a cielo abierto de Valparaíso. Madrid: Ediciones Complutense. Revista Arte, Individuo y Sociedad, Volumen 33, no3, 2021. ISSN: 1131-5598. Disponible en: https://doi.org/10.5209/aris.61328

DARDEL-CORONADO, M. El concepto de pintura no albergada y su práctica en la Escuela de Valparaíso (1969-1992). Santiago de Chile: Revista 180, no43, 2019. ISSN: 0718-669X. https://doi.org/10.32995/rev180.Num43.(2019).art-590

DIDI-HUBERMAN, G. L’homme qui marchait dans le couleur. Paris: Les Éditions de minuit, 2001- ISBN: 9782707317360

DROSTE, M. Bauhaus. Berlín: Editado por Bauhaus-Archiv, Taschen, 2019.

GARCÉS, A. La ciudad teatro, el lugar de la escena y otros lugares. Valparaíso: Ediciones universitarias de Valparaíso, Pontificia Universidad Católica de Valparaíso, 2019. ISBN: 978-956-17-0819-8.

LEÓN, A.M. Prisioneros de Ritoque, La ciudad abierta y el centro de detención. Santiago de Chile: Revista ARQ. Pontificia Universidad Católica de Chile. no92, abril, 2016. ISSN: 0716-0852. https://doi.org/10.4067/S071769962016000100009

IOMMI, G. Apertura de los terrenos de Ciudad Abierta, texto del Ágora del 4 enero de 1971. Ritoque: Publicado por Iommi,1971.

KANDINSKY, V. De lo espiritual en el arte. Barcelona: Editorial Planeta SA, Paidós Esenciales, 2019. ISBN: 978-84-4933422-1.

LUZA, D. Constitución de la extensión en común en la Ciudad Abierta. Barcelona: Tesis doctoral del Departamento de Proyectos Arquitectónicos de la Escuela Técnica de Arquitectura de Barcelona. Universidad Politécnica de Cataluña, 2013. Disponible en: https://docplayer.es > 85131082-Constitucion-de-la-ext...

MÉNDEZ, F. Catálogo Exposición Claudio Girola y Francisco Méndez, Sala Viña del Mar. Viña del Mar: Catálogo Exposición, 1981.

MÉNDEZ, F. De la grandeza, Lo sublime en la naturaleza. Santiago de Chile, 2015. ISBN: 978-956-362-093-1.

MIHALACHE, A. Huellas de Ciudad Abierta. Santiago de Chile: Revista ARQ. Pontificia Universidad Católica de Chile. no64, diciembre, 2006. ISSN: 0716-0852. https://doi.org/10.4067/S0717-69962006000300005

MILLÁN, P. Homo faber-homo ludens Torneos en la Escuela de Arquitectura y Diseño de Valparaíso (Chile). Alicante: Revista Innovación e Investigación en Arquitectura y Territorio. Universidad de Alicante. Volumen 7, n2, diciembre 2019. ISSN:2341-0515. https://doi.org/10.14198/i2.2019.2.03

MILLÁN, P. De la poesía a la experimentación: La Hospedería del Errante en Ciudad Abierta (Chile). Sevilla: Proyecto, Progreso, Arquitectura. N20_Más que arquitectura. Universidad de Sevilla. Mayo 2019. ISSN:2171-6897.

MONTEJO, E. Terredad. Mérida: Ediciones Actual, 2011.

PALMER, S. E. Vision Science: Photons to Phenomenology. Cambridge: MIT Press, 1999. ISBN: 978-02-621-6183-1.

RAHM, P. Evapored rooms and apartment for a young doctor. Santiago de chile. Revista ARQ. Pontificia Universidad Católica de Chile. no89, abril, 2015. ISSN: 0716-0852.

REYES, J. La huella de la Santidad de la Obra. Valparaíso: Escuela de Arquitectura y Diseño Pontificia Universidad Católica de Valparaíso - Casiopea, 2011. Disponible en: https:// wiki.ead.pucv.cl/La_Huella_de_la_Santidad_de_la_Obra.

SEGRE, R. Amereida en Valparaíso: un sueño utópico del siglo XX. Niteroi: Pragmatizes. Ano 1, no1, semestral, julho 2011. ISSN 2237-1508. https://doi.org/10.22409/pragmatizes1.1.a10335

TRÍAS, E. La razón fronteriza. Barcelona: Ediciones Destino SA, 1999. ISBN: 84-233-3089-3.

ZUBIRI, X. El hombre y Dios. Madrid: Alianza Editorial y Fundación Xavier Zubiri, 2017. ISBN: 978-84-206-0951-5.

ZUMTHOR, P. Atmósferas. Entornos arquitectónicos. Las cosas alrededor. Barcelona: Editorial Gustavo Gili SL, 2006. ISBN-13: 978-84-252-2117-0. 


\section{Bio}

Daniel Danés Grases, arquitecto urbanista por la Escuela de Arquitectura de la Universidad de Navarra desde el año 1989. Doctorando en la Escuela de Arquitectura de la Universidad Politécnica de Madrid. Su investigación versa sobre un análisis del color en la Ciudad Universitaria de Caracas y la Ciudad Abierta de Valparaíso. En 2018 realizó una estancia internacional de investigación en la Escuela de Arquitectura y diseño de la Pontificia Universidad Católica de Valparaíso.

Daniel Danés Grases, urban architect from the School of Architecture of the University of Navarra since 1989. Doctoral student at the School of Architecture of the Polytechnic University of Madrid. His research is about an analysis of color in the University City of Caracas and the Open City of Valparaíso. In 2018 he carried out an international research stay at the School of Architecture and Design of the Pontificia Universidad Católica de Valparaíso.

\section{Bio}

María José Pizarro Juanas es arquitecta por la ETSAM de Madrid desde el año 1995 y doctora por la ETSAM desde el año 2013. Profesora Contratada Doctora y Secretaria Académica del Departamento de Proyectos arquitectónicos desde el 2016. Miembro del comité de selección del MPAA desde el año 2016 y miembro del comité de selección de doctorado desde el año 2020. Es miembro de la comisión de doctorado del DPA desde el 2020.

María José Pizarro Juanas has been an architect by the ETSAM of Madrid since 1995 and a doctor by the ETSAM since 2013. Hired Professor Doctor and Academic Secretary of the Department of Architectural Projects since 2016. Member of the MPAA selection committee since the year 2016 and member of the doctoral selection committee since 2020. Member of the DPA doctoral committee since 2020.

\section{Bio}

Joaquín Ibañez Montoya, Doctor arquitecto y Profesor Emérito de la Escuela Técnica Superior de Arquitectura de la Universidad Politécnica de Madrid de la que fue subdirector y coordinador de la especialidad de Intervención en el Patrimonio Cultural. Coordinador del Comité Científico de la Red Internacional PHI Patrimonio Histórico +cultural Iberoamericano. Coordinador del Grupo de Cooperación "Patrimonio Cultural y Cooperación Internacional / PHI ".

Joaquín Ibañez Montoya, Doctor of Architecture and Emeritus Professor of the Higher Technical School of Architecture of the Polytechnic University of Madrid, of which he was deputy director and coordinator of the specialty of Intervention in Cultural Heritage. Coordinator of the Scientific Committee of the International Network IHP Ibero-American Historical + Cultural Heritage. Coordinator of the Cooperation Group "Cultural Heritage and International Cooperation / PHI".

\section{Bio}

Frank Marcano Requena, arquitecto. Universidad Central de Venezuela (UCV) 1973. Estudios de Maestría en Docencia Universitaria. Universidad Simón Bolívar 1974-1976. Doctorado de Urbanisme et Amenagement en L'Université de Paris 1982. Magister (DEA) Université de Paris (1978). Profesor de la Universidad Central de Venezuela (UCV). Fundador y Coordinador del Doctorado de Urbanismo y de la Maestría de Diseño Urbano del Instituto de Urbanismo de la Facultad de Arquitectura y Urbanismo de la UCV.

Frank Marcano Requena, architect. Central University of Venezuela (UCV) 1973. Master's Studies in University Teaching. Simón Bolívar University 1974-1976. Doctorate in Urbanism and Amenagement at L'Université de Paris 1982. Magister (DEA) Université de Paris (1978). Professor at the Central University of Venezuela (UCV). Founder and Coordinator of the Doctorate in Urbanism and the Master of Urban Design of the Institute of Urbanism of the Faculty of Architecture and Urbanism of the UCV. 
